\title{
Geologia, petrografia e geoquímica das rochas vulcânicas Uatumã na área sul de São Félix do Xingu (PA), Província Carajás
} Geology, petrographic and geochemical Uatumã volcanic area of southern São Félix do Xingu (PA), Carajás Province

Ana Tayla Rodrigues Ferreira*, Claudio Nery Lamarão

RESUMO: As rochas vulcânicas da área sul de São Félix do Xingu, estado do Pará, estão inseridas no contexto geológico da província geocronológica Amazônia Central, sudeste do cráton Amazônico. Estas rochas são dominantemente relacionadas à Formação Sobreiro e, subordinadamente, à Formação Santa Rosa, ambas pertencentes ao Grupo Uatumã de idade Paleoproterozoica. A Formação Sobreiro apresenta três fácies: fácies de fluxo de lavas subaérea de composição subalcalina; fácies de fluxo de lavas subaérea de composição calcioalcalina a shoshonítica; fácies vulcanoclástica subaérea. As rochas da Formaçấo Santa Rosa são enquadradas em uma única fácies denominada fácies de fluxo de lavas subaérea. $\mathrm{Na}$ Formação Sobreiro são encontrados andesitos basálticos, andesitos, traquiandesitos, traquitos, tufos de cristais félsicos, lapili-tufos e brechas polimíticas. Os litotipos da Formação Santa Rosa são riolitos. Os dados geoquímicos mostram que os conteúdos de $\mathrm{SiO}_{2}$ das rochas da Formação Sobreiro variam de 52,14 a $69,21 \%$ e as razóes $\mathrm{K}_{2} \mathrm{O} / \mathrm{Na}_{2} \mathrm{O}$ de 0,16 a 1,62 . Por outro lado, os vulcanitos da Formação São Rosa formam uma série evoluída com teores de $\mathrm{SiO}_{2}$ entre 72,27 e 77,14\% e razóes $\mathrm{K} / \mathrm{O} / \mathrm{Na}_{2} \mathrm{O}$ entre 1,50 e 2,12. A Formação Sobreiro tem caráter essencialmente calcioalcalino, discretamente transicional de calcioalcalino a shoshonítico, composiçáo metaluminosa a fracamente peraluminosa e assinatura tectônica de ambiente de arco vulcânico. A Formaçáo Santa Rosa apresenta composiçáo peraluminosa a fracamente metaluminosa, assinatura tipo A e afinidade tectônica intraplacas. As rochas vulcânicas da área sul apresentam perfeita correlação petrográfica, geoquímica e tectônica com os vulcanitos da área oeste/sudoeste de São Félix do Xingu.

PALAVRAS-CHAVE: rochas vulcânicas; rochas vulcanoclásticas; petrografia; geoquímica; fácies; Grupo Uatumã.

\begin{abstract}
The volcanic rocks southern São Félix do Xingu, Pará state, north Brazil, are geologically inserted in the geochronologic Amazonia Central province, southeastern Amazonian craton. These rocks are dominantly related to the Sobreiro Formation, and to the Santa Rosa Formation, both belonging to the Paleoproterozoic Uatuma group. Three facies of the Sobreiro Formation had been identified in this work: subaerial lava flow of subalkaline facies; subaerial lava flow of calc-alkaline to shoshonitic facies; subaerial volcaniclastic facies. The samples of the Santa Rosa Formation are subaerial lava flow. The Sobreiro Formation consists of basaltic andesite, andesite, traquiandesite, traquite, crystal tuffs, lapili-tuffs and polymictic breccias. The lithotypes of the Santa Rosa Formation are rhyolites. Rocks of the Sobreiro Formation have contents of $\mathrm{SiO}_{2}$ between 52.14 and $69.21 \%(w t \%)$ and $\mathrm{K}_{2} \mathrm{O} / \mathrm{Na}_{2} \mathrm{O}$ ratios between 0.16 and 1.62 . The Santa Rosa Formation form an evolved series with $\mathrm{SiO}_{2}$ contents between 72.27 and $77.14 \%(w t \%)$ and $\mathrm{K}_{2} \mathrm{O} / \mathrm{Na}_{2} \mathrm{O}$ ratios between 1.50 and 2.12. The Sobreiro Formation is mainly calc-alkaline, weakly transitional calc-alkaline to shoshonitic, has metaluminous to weakly peraluminous composition and tectonic signature of volcanic arc environment. The Santa Rosa Formation has peraluminous to weakly metaluminous composition and A-type signature with intraplate tectonic affinity. The volcanic rocks of the southern area have perfect correlation petrographic, geochemical and tectonic volcanites with the area west/southwest of São Félix do Xingu.
\end{abstract}

KEYWORDS: volcanic rocks; volcaniclastic rocks; petrography; geochemistry; facies; Uatumã Group.

Grupo de Pesquisa Petrologia de Granitoides, Instituto de Geociências, Universidade Federal do Pará - UFPA, Belém (PA), Brasil. Programa de Pós-graduação em Geologia e Geoquímica, Instituto de Geociências, Universidade Federal do Pará - UFPA, Belém (PA), Brasil. E-mail: taylaferreira@gmail.com, lamarao@ufpa.br

*Autor correspondente

Manuscrito ID 21713. Recebido em: 17/06/2011. Aprovado em: 18/02/2013 


\section{INTRODUÇÃO}

$\mathrm{Na}$ área sul de São Félix do Xingu, mais especificamente na porção leste da chamada segunda grande volta do Rio Xingu, centro-sul do Estado do Pará (Fig. 1), afloram rochas vulcânicas associadas ao Grupo Uatumá. Essas rochas estão inseridas no contexto geológico da província geocronológica Amazônia Central (Tassinari \& Macambira 2004, Santos et al. 2006), porção sudeste do cráton Amazônico. Geologicamente formam duas sequências distintas, uma denominada Formação Sobreiro (Macambira \& Vale 1997, Teixeira et al. 2002, Juliani \& Fernandes 2010, Fernandes et al. 2011) e a outra, denominada Formaçáo Santa Rosa (Juliani \& Fernandes 2010). Com o objetivo de incrementar a caracterização geológica e a cartografia dessas unidades, este trabalho se ateve ao estudo geológico, petrográfico e geoquímico dessas unidades.

\section{CONTEXTO GEOLÓGICO REGIONAL}

O quadro litoestratigráfico da regiáo de Sáo Félix do Xingu, segundo o mapa geológico do estado do Pará
(Vasquez et al. 2008), é representado pelas unidades arqueanas do Complexo Xingu, que corresponde a um conjunto de granitoides e ortognaisses de composiçóes granodioríticas a tonalíticas com variaçóes graníticas subordinadas, que têm idades de 2,97 Ga ( $\mathrm{Pb}-\mathrm{Pb}$ em zircão; Avelar et al. 1999), os quais foram variavelmente migmatizados há cerca de 2,86 Ga (U-Pb em RT; Machado et al. 1991), e do Grupo São Félix, que constitui sequências metavulcanosedimentares formadas, de modo geral, por metabasaltos com proporçóes variadas de rochas metavulcânicas e metavulcanoclásticas félsicas a intermediárias, além de formaçôes ferríferas bandadas e rochas metassedimentares clásticas. Sua idade neoarqueana inferida deve-se à forte correlação dessas sequências com aquelas dos Grupos Grão Pará (2,76 Ga; U-Pb em zircão; Wirth et al. 1986), Igarapé Salobo, Igarapé Bahia, Igarapé Pojuca, Rio Novo, Aquiri e São Sebastiấo. Um conjunto de granitoides calcioalcalinos denominado Granitos Tipo I Indiferenciados (1,92 Ga; RbSr em RT; Vasquez et al. 2008), o Grupo Uatumá (1,88 Ga; Macambira \& Vale 1997), os granitoides anorogênicos da Suíte Intrusiva Velho Guilherme (1887 \pm 5 e $1862 \pm 16 \mathrm{Ma}$; $\mathrm{Pb}-\mathrm{Pb}$ em zircão; Teixeira et al. 2002 e Pinho et al. 2006,

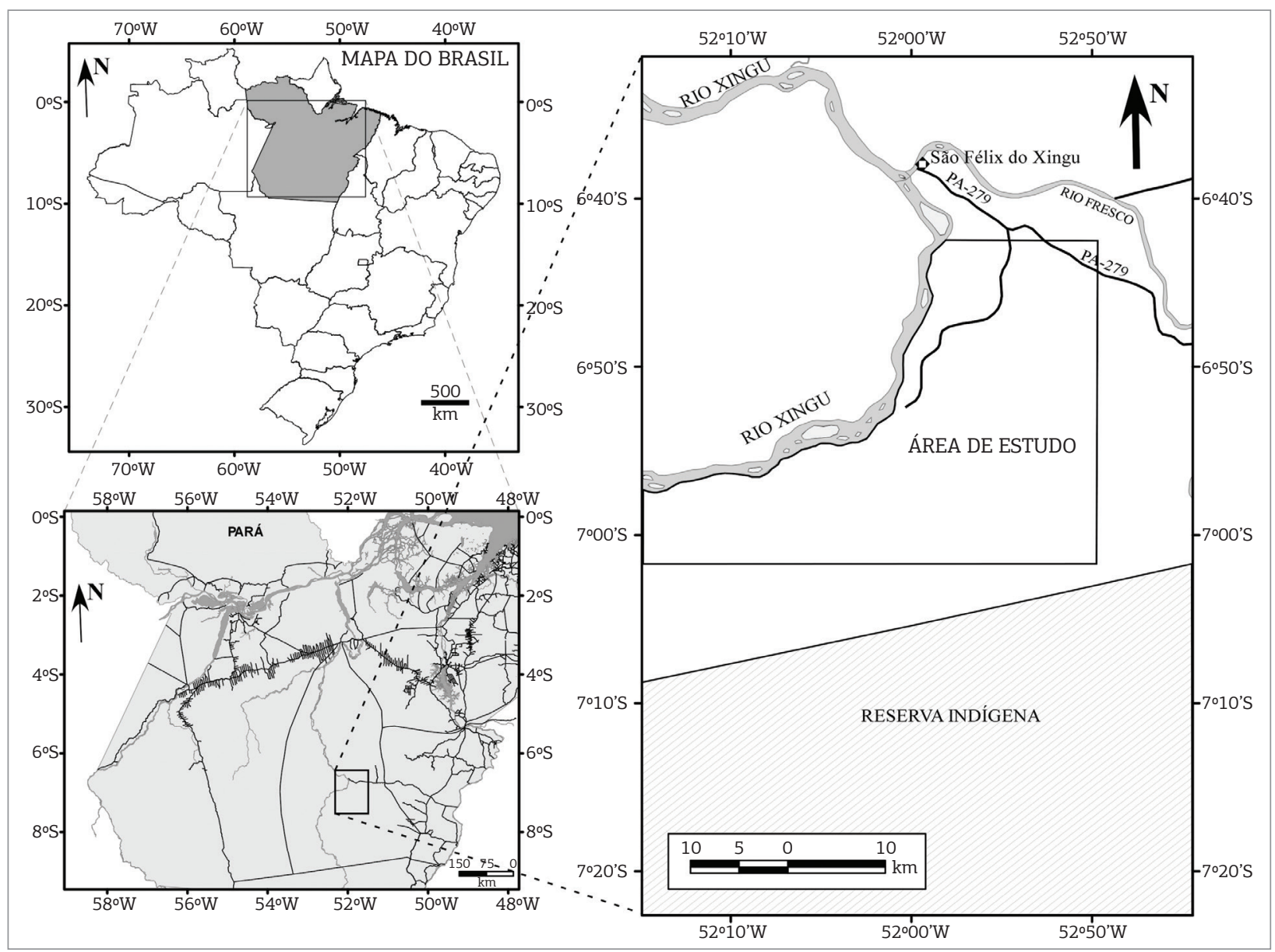

Figura 1. Mapa de localização da área sul de São Félix do Xingu. 
respectivamente) e a Formação Triunfo, rochas sedimentares com contribuição significativa de fontes detríticas principalmente de origem vulcânica félsica, relacionadas a um estágio avançado da evolução de um rift (tafrogênese) implantado durante o Orosiriano e o Estateriano (Silva et al. 1974), compóem o Proterozoico aflorante nesta região. O Fanerozoico é representado pelo Diabásio Cururu, lateritos e depósitos aluvionares (Macambira \& Vale 1997).

\section{GRUPO UATUMÃ}

O Grupo Uatumã compreende a parte vulcânica de uma sequência vulcano-sedimentar Paleoproterozoica que preenche a Bacia do Médio Xingu (Macambira \& Vale 1997). Constitui uma unidade bimodal formada durante um evento paleoproterozoico, sendo parte do Supergrupo Uatumá (Fernandes 2009, Juliani \& Fernandes 2010). A unidade basal deste Grupo corresponde à Formaçáo Sobreiro. A unidade superior, em trabalhos recentes é denominada Formação Santa Rosa (Juliani \& Fernandes 2010, Fernandes et al. 2011).

\section{Formação Sobreiro}

A Formação Sobreiro, encontrada em ambas as margens da chamada segunda grande volta do Rio Xingu, é uma associação vulcânica de composição dominantemente intermediária e, subordinadamente, félsica (Macambira \& Vale 1997, Teixeira et al. 2002, Juliani \& Fernandes 2010) de idade $1880 \pm 6 \mathrm{Ma}$ (dacito; $\mathrm{Pb}-\mathrm{Pb}$ em zircáo; Pinho et al. 2006). Compreende fácies de fluxo de lavas, com estruturas de fluxo horizontal a sub-horizontal, representada por andesitos basálticos, andesitos, lati-andesitos, latitos, quartzo latitos, dacitos e riodacitos (classificação segundo o diagrama R1 versus $\mathrm{R} 2$ de De La Roche et al. 1980 utilizada por Fernandes et al. 2011), e fácies vulcanoclástica representada por brechas autoclásticas, tufos de cristais máfico, lapili-tufos e brechas polimíticas maciças (Juliani \& Fernandes 2010). Teixeira et al. (2002), com base em estudos de isótopos de $\mathrm{Nd}$ em andesitos da Formação Sobreiro, determinaram valor $\varepsilon_{\mathrm{Nd}}$ igual a -10,1 e idade $\mathrm{T}_{\mathrm{DM}}$ de 3,11 Ga. Semelhantemente, Fernandes et al. (2011), a partir de amostras de lati-andesitos e andesitos, determinaram valores de $\varepsilon_{\mathrm{Nd}}$ entre $-9,61$ e $-4,56$ e intervalo de idades $\mathrm{T}_{\mathrm{DM}}$ entre 2,89 e 2,49 Ga.

\section{Formação Santa Rosa}

A Formação Santa Rosa, mais expressiva nas porçóes oeste e sudoeste de Sáo Félix do Xingu, compreende uma associação vulcânica félsica gerada por episódios multicíclicos, explosivo e efusivo (Juliani \& Fernandes 2010).
Fernandes et al. (2011) dataram, pelo método $\mathrm{Pb}-\mathrm{Pb}$ em zircão, amostras de tufo de cinza e riolito desta formação e obtiveram valores respectivos de $1884 \pm 1,7 \mathrm{Ma}$ e $1879 \pm 2$ Ma. Geoquimicamente, as rochas da Formação Santa Rosa compreendem álcali riolitos e subordinados riolitos e riodacitos peraluminosos a levemente metaluminosos com características subalcalinas a alcalinas, e afinidade geoquímica de granitos intraplacas (Fernandes, Lamarão \& Teixeira 2006, Fernandes et al. 2011).

\section{MATERIAIS E MÉTODOS}

As observaçóes de campo foram realizadas pela tomada de pontos-afloramentos dos diversos vulcanitos aflorantes, bem como do substrato mais antigo, a fim de delimitar as áreas de ocorrência das rochas vulcânicas do Grupo Uatumã. Observaçóes texturais e mineralógicas foram realizadas em 71 lâminas polidas dos diversos litotipos encontrados. Isso possibilitou avaliar o grau de preservaçáo dessas rochas e a seleção de 24 exemplares de considerável representatividade para análise química em rocha total.

As análises geoquímicas foram realizadas por Inductively Coupled Plasma - Emission Spectrometry (ICP-ES) para elementos maiores e menores, e por Inductively Coupled Plasma - Mass Spectrometry (ICP-MS) para os elementos traços incluindo elementos terras raras, no Acme Analytical Laboratories Ltd. (Vancouver, Canadá).

\section{RESULTADOS}

\section{Geologia e faciologia}

As rochas vulcânicas encontradas na área sul de São Félix do Xingu afloram na forma morrotes de topo abaulado que despontam na topografia em cotas entre 200 e $270 \mathrm{~m}$ acima de uma área de relevo dissecado. Comumente afloram também na forma de blocos submétricos a métricos rolados ou in situ e, menos comumente, na forma de lajeiros com áreas de exposição de dimensôes métricas a decamétricas.

A Formação Sobreiro foi dividida em pelo menos três fácies (Fig. 2): 1) fácies de fluxo de lavas subaérea de composição calcioalcalina, constitui a fácies dominante da área em questão; 2) fácies de fluxo de lavas subaérea de composição calcioalcalina a shoshonítica; e, 3) fácies vulcanoclástica subárea. A Formação Santa Rosa é caracterizada por rochas com aspecto de fluxo de lavas aqui agrupadas na fácies denominada fácies de fluxo de lavas subárea (Fig. 2).

A vegetação de pasto ou nativa, em muitas porçóes da área sul de São Félix do Xingu, dificulta ou impossibilita 
que sejam feitas observaçóes claras das relaçôes de contato entre as diversas fácies de cada formação, entre as formaçôes, ou entre elas e o substrato mais antigo.

\section{Petrografia}

As rochas vulcânicas da área sul de São Félix do Xingu são texturalmente muito diversificadas. Embora as rochas com aspecto de fluxo de lavas sejam as mais comuns, rochas de aspecto vulcanoclástico têm expressão significativa.

\section{Formaçáo Sobreiro}

A Formação Sobreiro, principal unidade vulcânica da área sul de São Félix do Xingu, é dominantemente formada por rochas relacionadas a processos de fluxo de lavas de aspecto afanítico ou porfirítico de matriz afanítica. Subordinadamente, compreende rochas de aspecto vulcanoclástico de granulação desde cinza até blocos.

As rochas relacionadas a fluxo de lavas (fácies 1 e 2) da Formaçáo Sobreiro foram petrograficamente nomeadas segundo os critérios recomendados por McPhie, Doyle \& Allen (1993) que levam em consideração as diversidades texturais e a natureza e proporçáo modal dos fenocristais. Já os litotipos vulcanoclásticos foram classificados segundo o diagrama de Fisher (1966), que se baseia na granulometria e conteúdo de fragmentos minerais ou líticos presentes na rocha.

\section{Fácies de fluxo de lavas subaérea de composição calcioalcalina}

Traquiandesitos são os litotipos dominantes da Formação Sobreiro, sendo descritos em menor proporção, andesitos basálticos, andesitos e traquitos. De modo geral, essas rochas são de cor cinza escura a preta, variam de microporfiríticas a porfiríticas, por vezes, glomeroporfiríticas, cuja matriz, sempre muito fina, varia de microcristalina a criptocristalina, vitrofírica e, localmente, amigdaloidal. A assembleia de fenocristais dessas rochas inclui cristais euédricos de anfibólio, e menos comumente de clinopiroxênio e plagioclásio; além desses, nos litotipos mais evoluídos são também encontrados fenocristais de feldspato potássico. A matriz é formada mineralogicamente por finos agregados de plagioclásio e biotita, além de anfibólio e opacos, apatita e quartzo presentes em algumas amostras. Micrólitos de feldspato potássico são identificáveis apenas por análise química pontual por microscopia eletrônica de varredura. Epídoto, minerais opacos, clorita, argilominerais e biotita são minerais secundários frequentes.

Segundo os critérios de McPhie, Doyle \& Allen (1993), essas rochas podem ser subdivididas nos seguintes litotipos petrográficos: plagioclásio-anfibólio andesito basáltico microporfirítico, plagioclásio-clinopiroxênio-anfibólio andesito microporfirítico a porfirítico, plagioclásio-anfibólio andesito microporfirítico, feldspato

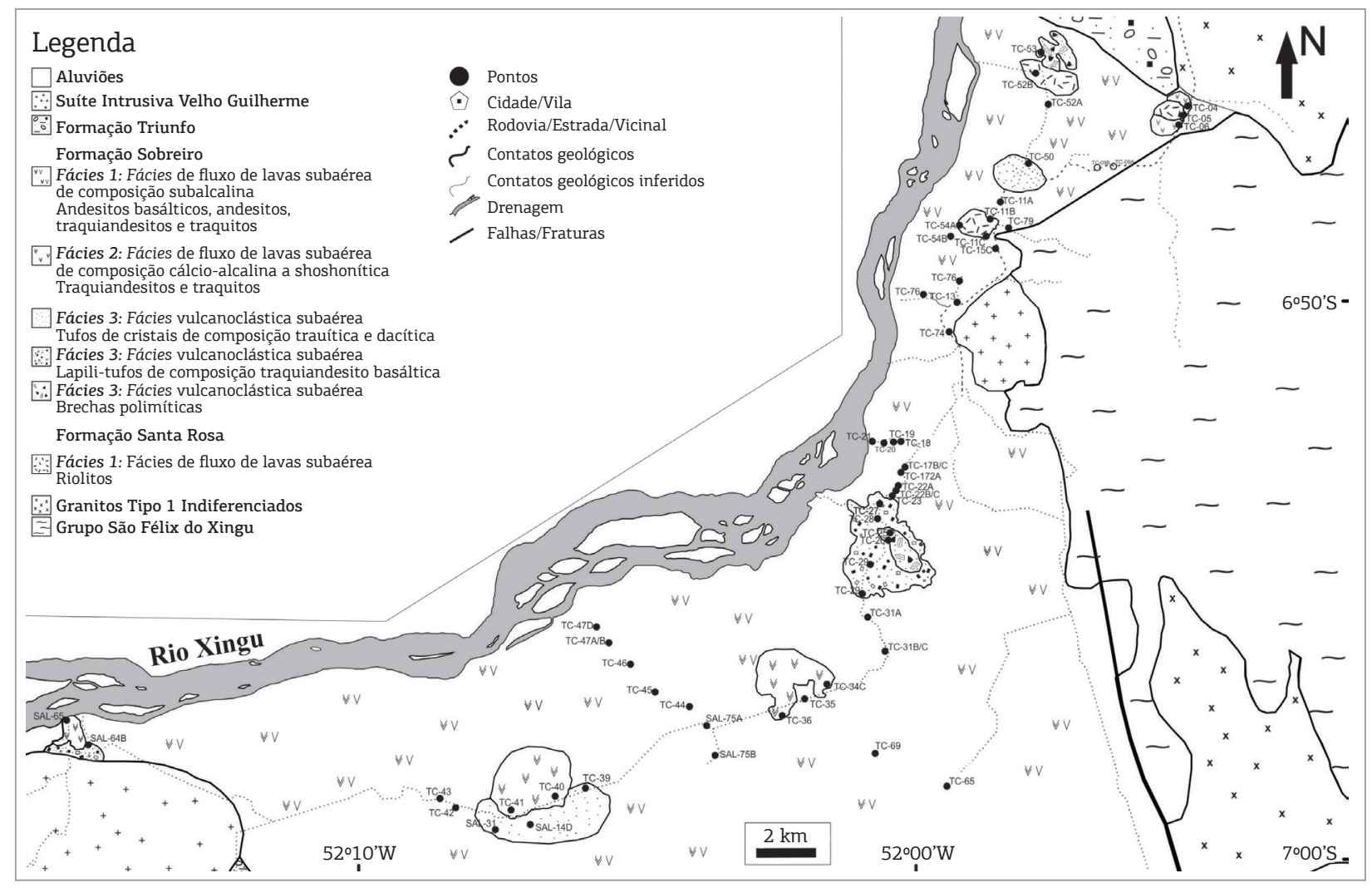

Figura 2. Mapa geológico esquemático da área sul de São Félix do Xingu, modificado de Vasquez et al. (2008). 
potássico-plagioclásio-clinopiroxênio traquiandesito porfrítico, feldspato potássico-plagioclásio-anfibólio traquiandesito microporfirítico a porfirítico, plagioclásio-anfibólio traquiandesito microporfirítico, anfibólio-feldspato potássico-plagioclásio traquiandesito porfirítico, plagioclásiofeldspato potássico-anfibólio traquiandesito microporfirítico a porfirítico, anfibólio-feldspato potássico-plagioclásio traquito porfirítico e plagioclásio-feldspato potássico traquito porfirítico.

\section{Fácies de fluxo de lavas subaérea de composiçáo calcioalcalina a shoshonitica}

Traquiandesitos calcioalcalinos a shoshoníticos são os litotipos dominantes desta fácies. Em menor proporção, são descritos traquitos calcioalcalinos a shoshoníticos. Esses traquiandesitos são petrograficamente diversificados variando desde marrom avermelhado a cinza escuro; têm textura porfirítica ou microporfirítica. Sua assembleia de fenocristais, com conteúdos modais entre 20 e $45 \%$, inclui cristais euédricos de anfibólio, clinopiroxênio, plagioclásio e, por vezes, feldspato potássico. Segundo os critérios de McPhie, Doyle \& Allen (1993), essas rochas poderiam ser subdivididas em plagioclásio-anfibólio-clinopiroxênio traquiandesito porfirítico, anfibólio-feldspato potássico-plagioclásio traquiandesito microporfirítico a porfirítico, feldspato potássico-plagioclásio-anfibólio traquiandesito porfirítico. A matriz dessas rochas varia de criptocristalina a vitrofírica com porçóes amigdaloidais. Sua composição é quartzo-feldspática com cristais diminutos de anfibólio. Cromo-espinélio e apatita aparecem como fases acessórias. Minerais opacos indistintamente dispersos, epídoto, carbonatos, titanita e clorita são as principais fases secundárias. Argilominerais são encontrados como produto de alteração incipiente dos fenocristais feldspáticos.

Os traquitos são macroscopicamente distintos dos traquiandesitos. São rochas de cor rosa e aspecto porfirítico com cerca de $60 \%$ de fenocristais de granulação média a grossa. Tais fenocristais são dominantemente cristais de feldspato potássico leve a moderadamente alterados para argilominerais e, subordinadamente, plagioclásio e quartzo. Os cristais de quartzo são subédricos a euédricos com feiçōes de reabsorção. Fenocristais reliquiares de anfibólio epidotizados, embora raros, são encontrados. A matriz é microcristalina e tem composição quartzo-feldspática. Agregados muito finos de carbonatos associados a epídoto, comumente contornando os fenocristais de plagioclásio, são frequentemente observados. Minerais opacos, epídoto, argilominerais, carbonatos e clorita são fases secundárias. De acordo com os critérios de McPhie, Doyle \& Allen (1993), podem ser petrograficamente nomeados anfibólio-feldspato potássico-plagioclásio traquito.

\section{Fácies vulcanoclástica subaérea}

Os litotipos que compóem essas fácies, conforme a classificação de Fisher (1966), são tufos félsicos de cristais (rocha de textura vulcanoclástica cujos constituintes, em sua grande maioria, são fragmentos de granulação inferior a $2 \mathrm{~mm}$ ). Em amostras de mão, essas rochas são muito semelhantes àquelas de aspecto de fluxo de lavas, porém em lâmina distinguemse por suas texturas vulcanoclásticas definida pela presença de cristaloclastos (entre 70 e 85\%) de granulação fina e formas angulosas. São rochas afaníticas, maciças, de cor cinza escura ou esverdeada, cuja assembleia mineralógica identificada é representada, sobretudo, por fragmentos de cristais de quartzo, plagioclásio e, subordinadamente, feldspato potássico com ou sem maclamento xadrez. Cristais de zircão fortemente alterados e apatita são comumente encontrados. Vidro desvitrificado, epídoto, titanita, opacos e clorita são fases secundárias. Localmente, são encontradas vênulas preenchidas por quartzo e/ou epídoto. Intercrescimentos esferulíticos do tipo axiolítico, como produto da desvitrificaçáo de vidro, e cristais de muscovita são identificados em algumas amostras.

Os lapili-tufos são constituídos por mais de $75 \%$ de fragmentos de cristais e líticos de granulação entre 2 e 64 mm. São rochas de cor marrom esverdeada cujos fragmentos líticos são textural e mineralogicamente diversos e nadam em uma matriz rica em cristaloclastos de tamanhos variados de anfibólio e plagioclásio e, em menor quantidade, fragmentos cristalinos de quartzo e feldspato potássico. Embora, de modo geral, os limites dos fragmentos líticos sejam determinados pela presença de cristais quebrados nos contatos dos fragmentos com a matriz, algumas vezes é possível observar fenocristais de anfibólio compartilhados tanto pelo fragmento quanto pela matriz da rocha.

As brechas polimíticas são essencialmente constituídas por blocos líticos de natureza e tamanhos diversos. Essas rochas têm cerca de $80 \%$ de fragmentos líticos de pelo menos 4 tipos diversos, os demais $20 \%$ constituem a matriz. Tal matriz é rica em cristaloclastos de plagioclásio e anfibólio e, em menor quantidade, feldspato potássico e quartzo. Embora alguns fragmentos líticos apresentem feiçôes de reabsorção e composição mineralógica semelhante à da matriz piroclástica, tais rochas não foram consideradas apropriadas para análises químicas em rocha total.

\section{Formação Santa Rosa}

Os poucos afloramentos da Formação Santa Rosa encontrados são constituídos por rochas de aspecto de fluxo de lavas, as quais foram agrupadas em uma única fácies denominada fácies de fluxo de lava subaérea.

\section{Fácies de fluxo de lavas subaérea}

Riolitos de aspecto microporfirítico e porfirítico são as rochas que compóem essa fácies. Tais riolitos são de cor 
rosa e constituídos por fenocristais de granulação fina, média ou grossa. Esses fenocristais ocupam entre 15 e 30\% da rocha e são representados por cristais de feldspato potássico, quartzo e, por vezes, plagioclásio. Segundo os critérios de McPhie, Doyle \& Allen (1993), podem ser petrograficamente nomeados como plagioclásio-feldspato potássico-quartzo riolito e feldspato potássico-quartzo riolito. A matriz dessas rochas varia com porçóes de textura microcristalina de composição quartzo-feldspática, localmente, granofíricas a esferulítica. Zircão e muscovita são os minerais acessórios presentes em algumas amostras. Epídoto, argilominerais, mica branca, clorita, minerais opacos e, subordinadamente, titanita e fluorita, figuram como fases minerais secundárias.

\section{Geoquímica}

As rochas vulcânicas da área sul de São Félix do Xingu são associaçóes de composiçóes distintas que variam desde intermediárias até félsicas, sendo representadas dominantemente pelas rochas efusivas subalcalinas (calcioalcalinas) (fácies 1), em menor proporção, pelas rochas efusivas calcioalcalinas a shoshoníticas (fácies 2) e explosivas (fácies 3) da Formação Sobreiro e, muito subordinadamente, pelos riolitos da Formação Santa Rosa (Fig. 2). Os dados geoquímicos dessas rochas encontram-se dispostos na Tab. 1.

De acordo com o diagrama total de álcalis versus sílica (Le Bas et al. 1986; Fig. 3A), a Formação Sobreiro é representada por andesitos basálticos, traquiandesitos subalcalinos, andesitos e traquitos $\left(\mathrm{SiO}_{2}=53,97\right.$ a $62,27 \%$, razóes $\mathrm{K}_{2} \mathrm{O} / \mathrm{Na}_{2} \mathrm{O}=0,16$ a 1,05 ; fácies 1 ), por traquiandesitos e traquitos calcioalcalinos a shoshoníticos $\left(\mathrm{SiO}_{2}=54,97 \mathrm{a}\right.$ $66,71 \%$, razóes $\mathrm{K}_{2} \mathrm{O} / \mathrm{Na}_{2} \mathrm{O}=0,60$ a 1,62; fácies 2), por tufos (fácies 3) de composiçóes traquíticas $\left(\mathrm{SiO}_{2}=64,41\right.$ a $65,34 \%$, razóes $\mathrm{K}_{2} \mathrm{O} / \mathrm{Na}_{2} \mathrm{O}=1,23$ a 1,49) e dacíticas $\left(\mathrm{SiO}_{2}=69,21 \%\right.$, razão $\left.\mathrm{K}_{2} \mathrm{O} / \mathrm{Na}_{2} \mathrm{O}=0,57\right)$ e, por lapili-tufos de composição traquiandesitos basálticos $\left(\mathrm{SiO}_{2}=52,14 \mathrm{a}\right.$ $53,97 \%$, razóes $\mathrm{K}_{2} \mathrm{O} / \mathrm{Na}_{2} \mathrm{O}=0,51$ a 0,99; fácies 3). Todas as amostras analisadas da Formação Santa Rosa plotam no campo dos riolitos com teores de $\mathrm{SiO}_{2}$ entre 72,27 e 77,14\% e razóes $\mathrm{K}_{2} \mathrm{O} / \mathrm{Na}_{2} \mathrm{O}$ entre 1,5 a 2,12 (Tab. 1). A Formação Santa Rosa constitui, portanto, uma série evoluída.

No diagrama $\mathrm{K}_{2} \mathrm{O}$ versus $\mathrm{SiO}_{2}$ de Peccerillo \& Taylor (1976) (Fig. 3B), é possível observar que, a exceção da TC$11 \mathrm{~A}$, todas as demais amostras da fácies 1 plotam nos campos das séries calcioalcalinas de médio e alto potássio. $\mathrm{O}$ maior conteúdo de $\mathrm{K}_{2} \mathrm{O}$ nos andesito basálticos em relação a duas amostras de traquiandesitos sugere que tais rochas não derivaram de um mesmo magma original por processos de cristalizaçáo fracionada, visto que numa série magmática o potássio, como elemento incompatível, tenderia a enriquecer nas rochas mais evoluídas. Alternativamente, tal distribuição das amostras poderia ser justificada por diferentes graus de interação e contaminação crustal durante o processo de ascensão do magma. As amostras da fácies 2 , embora em número reduzido, mostram preferência pelo campo das séries shoshoníticas, com um trend de inclinação positiva que inicia no campo das séries calcioalcalinas de alto K. Ainda nesse diagrama, observa-se que as amostras da fácies 3 plotam dominantemente no campo das séries shoshoníticas, com apenas uma amostra incidindo no campo das séries calcioalcalinas de médio $\mathrm{K}$, e uma no campo das séries calcioalcalinas de alto K. Tal comportamento pode ser explicado pela heterogeneidade dos materiais que as compóem.

No diagrama triangular AFM $\left(\mathrm{A}=\mathrm{Na}_{2} \mathrm{O}+\mathrm{K}_{2} \mathrm{O}\right.$ versus $\mathrm{F}=\mathrm{FeO}^{*}$ versus $\mathrm{M}=\mathrm{MgO}$; Fig. $3 \mathrm{C}$ ) de Irvine e Baragar (1971), as amostras da Formaçáo Sobreiro plotam no campo das séries calcioalcalinas. Apesar disso, é possível observar, ainda, que à medida que o $\mathrm{MgO}$ diminui e a soma $\mathrm{Na}_{2} \mathrm{O}+\mathrm{K}_{2} \mathrm{O}$ aumenta tem-se um continuo e gradual aumento do $\mathrm{FeO}^{*}$ no sentido andesito-basáltico-andesito-traquiandesito-traquito. Duas amostras, TC-11A e TC-54B, chegam a atingir o limite entre séries calcioalcalina e toleítica. Este comportamento pode indicar que a Formação Sobreiro possivelmente não representa uma série magmática calcioalcalina típica.

Quanto ao índice de saturação em alumina de Shand (1950) (Fig. 3D; Tab. 1), a Formação Santa Rosa é peraluminosa a fracamente metaluminosa, com apenas uma amostra (TC-11B) com razão $\mathrm{A} / \mathrm{CNK}<1$. Já a fácies 1 da Formação Sobreiro é inteiramente metaluminosa, tendo valores de $\mathrm{A} / \mathrm{CNK}$ menores que um em todas as amostras analisadas. Por outro lado, as fácies 2 e 3 distribuem-se entre os campos metaluminoso e peraluminoso.

Em diagramas de Harker (Fig. 4) é possível observar que, em relação à Formação Sobreiro, as amostras da Formação Santa Rosa apresentam, de modo geral, os menores conteúdos de $\mathrm{TiO}_{2}, \mathrm{FeO}, \mathrm{MgO}, \mathrm{CaO}$ e $\mathrm{P}_{2} \mathrm{O}_{5}$, e uma correlação negativa com a sílica. No que concerne a Formação Sobreiro se observa, de modo geral (Fig. 4), que as diversas amostras da fácies 1 não exibem trends de correlação que possam indicar processos de cristalização fracionada a partir de um único magma inicial homogêneo. Pelo contrário, nos litotipos com análises em mais de uma amostra, como no caso dos andesitos e traquiandesitos, observa-se um considerável espalhamento vertical das amostras mesmo num intervalo restrito do conteúdo de $\mathrm{SiO}_{2}$. Esta falta de padrão reforça a hipótese de que, pelo menos, parte dos traquiandesitos não seja produto de cristalização fracionada dos andesitos basálticos ou mesmo andesitos. As poucas análises das fácies 2 e 3 torna difícil interpretaçôes de suas distribuiçốes nesses diagramas. 
Tabela 1. Composições químicas das rochas vulcânicas das formações Sobreiro e Santa Rosa, área sul de São Félix do Xingu

\begin{tabular}{|c|c|c|c|c|c|c|c|c|c|c|c|c|c|c|c|c|c|c|c|c|c|c|c|c|}
\hline Unidade & \multicolumn{21}{|c|}{ Formação Sobreiro } & \multirow{2}{*}{\multicolumn{3}{|c|}{$\begin{array}{c}\text { Formação } \\
\text { Santa Rosa } \\
1\end{array}$}} \\
\hline Fácies & \multicolumn{12}{|c|}{1} & \multicolumn{4}{|c|}{2} & \multicolumn{5}{|c|}{3} & & & \\
\hline Tipo & AB & \multicolumn{3}{|c|}{ AN } & \multicolumn{7}{|c|}{ TA } & TR & \multicolumn{3}{|c|}{ TA } & TR & \multicolumn{2}{|c|}{ TAB } & \multicolumn{2}{|c|}{ TR } & DAC & \multicolumn{3}{|c|}{ RL } \\
\hline 营 & $\stackrel{M}{\stackrel{M}{\prime}}$ & હ্ّ & 睰 & $\begin{array}{l}\text { ஸ્ } \\
\text { ư }\end{array}$ & 芯 & ن্ & ঠ্ণ & 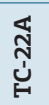 & \begin{tabular}{l}
\multirow{\jmath}{~}{} \\
ư
\end{tabular} & 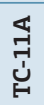 & પn & 悉 & 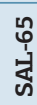 & 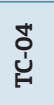 & $\begin{array}{l}\stackrel{p}{ } \\
\text { ú }\end{array}$ & ণ্ণি & 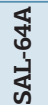 & 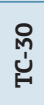 & लै & $\begin{array}{l}\text { 오 } \\
\text { ư }\end{array}$ & ले & 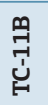 & $\begin{array}{l}\text { ֻ } \\
\text { ư }\end{array}$ & 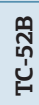 \\
\hline
\end{tabular}

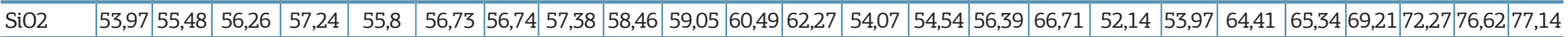

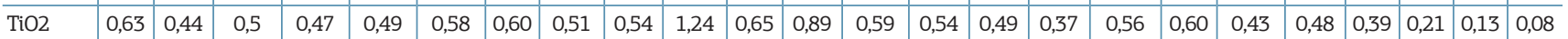

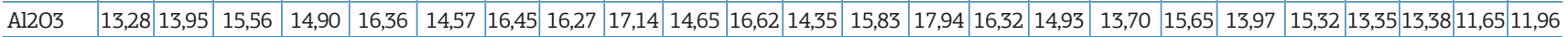

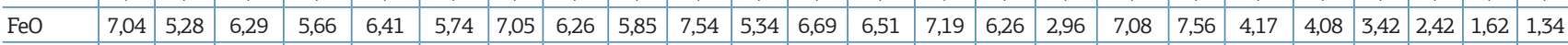
\begin{tabular}{l|l|l|l|l|l|l|l|l|l|l|l|l|l|l|l|l|l|l|l|l|l|l|l|l|l|l|}
\hline MnO & 0,11 & 0,08 & 0,11 & 0,10 & 0,12 & 0,17 & 0,16 & 0,09 & 0,10 & 0,15 & 0,11 & 0,13 & 0,11 & 0,18 & 0,11 & 0,05 & 0,12 & 0,13 & 0,07 & 0,08 & 0,07 & 0,11 & 0,02 & 0,01 \\
\hline
\end{tabular}

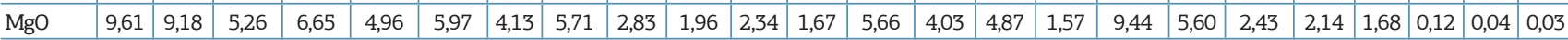

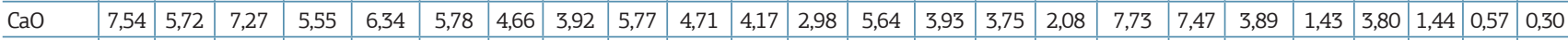

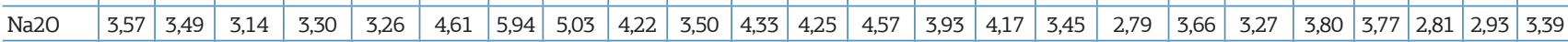

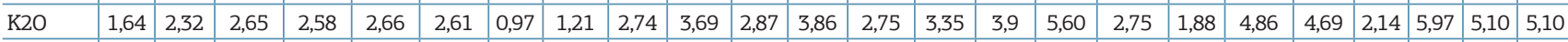
\begin{tabular}{l|l|l|l|l|l|l|l|l|l|l|l|l|l|l|l|l|l|l|l|l|l|l|l|l}
\hline P2O5 & 0,27 & 0,24 & 0,21 & 0,21 & 0,23 & 0,34 & 0,34 & 0,25 & 0,31 & 0,65 & 0,24 & 0,3 & 0,31 & 0,30 & 0,21 & 0,13 & 0,49 & 0,21 & 0,21 & 0,15 & 0,19 & 0,02 & 0,02 & 0,01 \\
\hline
\end{tabular}

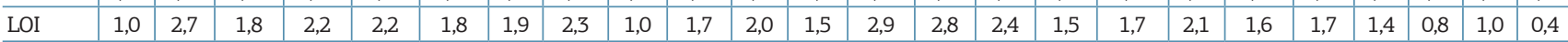

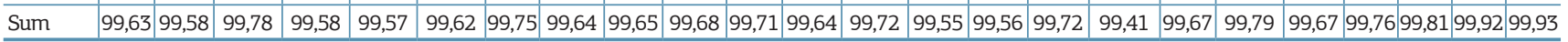
Traços (ppm)

\begin{tabular}{|c|c|c|c|c|c|c|c|c|c|c|c|c|c|c|c|c|c|c|c|c|c|c|c|c|}
\hline $\mathrm{Ba}$ & 710 & 1118 & 1188,3 & 1387 & 1401,3 & 1147 & 750 & 1079 & 1575 & 1365 & 1299 & 2005 & 1387 & 2149 & 2540 & 1497 & 2654 & 1020 & 1457,3 & 1919 & 797 & 1097 & 143 & 99 \\
\hline $\mathrm{Sr}$ & 922,2 & 974,3 & 1117,7 & 1056,6 & 1476,6 & 1033,7 & 496,5 & 1019,8 & 889,8 & 627,2 & 665,5 & 336,3 & 1312,2 & 878,7 & 567,9 & 417,9 & 1431,1 & 761,3 & 610,6 & 472,4 & 715,4 & \begin{tabular}{|l|l}
4 & 95,5
\end{tabular} & 39,3 & 47,6 \\
\hline $\mathrm{Zr}$ & 91,1 & 95,8 & 86,2 & 93,3 & 93,8 & 142,3 & 116,4 & 98,4 & 124,8 & 193,2 & 140,6 & 232,1 & 108,0 & 91,9 & 91,8 & 228,2 & 109,4 & 74,1 & 200,7 & 150,4 & 167,3 & 3306,7 & 215,9 & 204,9 \\
\hline $\mathrm{Y}$ & 10,0 & 7,7 & 9 & 8,7 & 0 & 10,6 & 12,1 & 10,5 & 11,2 & 30,5 & 15,5 & 31,7 & 11,8 & 10,8 & 10,7 & 15,4 & 9,7 & 10,7 & 10,5 & 17,5 & 20,1 & 40,4 & 59,5 & 83,6 \\
\hline $\mathrm{Hf}$ & 2,5 & 2,8 & 2,3 & 2 & 2,3 & 3,6 & 2 & 2,8 & 3,5 & 5,3 & 4,0 & 6 & 2,9 & 2,6 & 2,3 & 6,2 & 2,9 & 2,2 & 5,6 & 4,6 & 4,8 & 8,2 &, 5 & 9,0 \\
\hline $\mathrm{Nb}$ & 3,2 & 3,0 & 2,5 & 2,3 & 2,5 & 3 & 9,0 & ב, & 4,4 & 9,6 & 6,8 & 11,4 & 3,1 & 4,1 & $2, r$ & 0,1 & 3,1 & $\angle$ & $0, f$ & 7,1 & 9,1 & 14,4 & 18,3 & 20,3 \\
\hline $\mathrm{Ga}$ & 17,4 & 16,3 & 20.1 & 16,9 & 20.5 & 20,5 & 17,6 & 18,4 & 19,6 & 19,3 & 18,5 & 18,1 & 19.2 & 17,5 & 16,6 & 17,9 & 16.8 & 19,7 & 15.4 & 17,7 & 15,0 & 19,3 & 17,7 & 20,9 \\
\hline $\mathrm{Rb}$ & 97,4 & 36,4 & 41,5 & 39,1 & 45,2 & 45,1 & 40,5 & 36,7 & 53,9 & 134,0 & 92,6 & 122,6 & 53,4 & 84,4 & 63,8 & 135,6 & 84,8 & 32,9 & 112,2 & 121,1 & 53,8 & 264,9 & 175,1 & 148,2 \\
\hline $\mathrm{Ta}$ & 0,2 & 0,1 & 0,1 & 0,1 & 0,2 & 0,3 & 0,5 & 0,2 & 0,3 & 0,8 & 0,5 & 0,8 & 0,2 & 0,3 & 0,1 & 0,7 & 0,2 & 0,1 & 0,5 & 0,5 & 0,6 & 1,1 & 1,6 & 1,5 \\
\hline Th & 1,3 & 2,0 & 1,8 & 1,5 & 5,4 & 4,3 & 7,6 & 3,0 & 4,2 & 11,1 & 7,2 & 15,9 & 1,9 & 4,8 & 1,9 & 11,0 & 2,6 & 2,1 & 7,8 & 10,4 & 11,0 & 21,9 & 34,8 & 28,4 \\
\hline
\end{tabular}
ETR (ppm)

\begin{tabular}{l|l|l|l|l|l|l|l|l|l|l|l|l|l|l|l|l|l|l|l|l|l|l|l|l}
\hline La & 17,5 & 21,7 & 16,1 & 17,8 & 20,6 & 30,2 & 35,5 & 21,5 & 29,0 & 44,9 & 32,8 & 54,7 & 23,6 & 24,5 & 18,5 & 34,6 & 21,0 & 16,1 & 30,1 & 31,0 & 32,7 & 67,4 & 81,5 & 67,3 \\
\hline
\end{tabular}

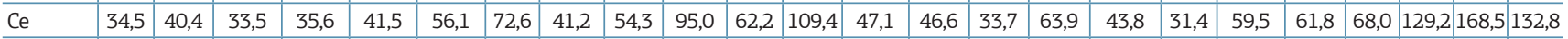

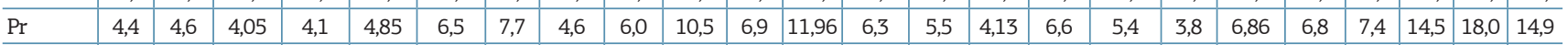

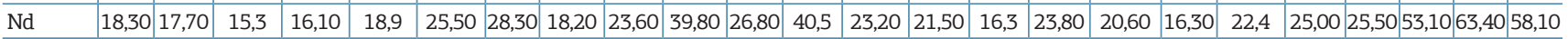

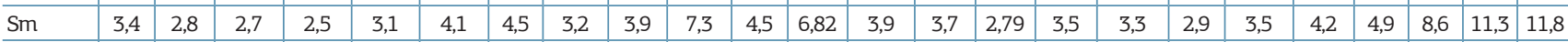
\begin{tabular}{l|l|l|l|l|l|l|l|l|l|l|l|l|l|l|l|l|l|l|l|l|l|l|l|l|l|l|}
\hline $\mathrm{Eu}$ & 1,09 & 0,84 & 0,82 & 0,84 & 0,82 & 1,14 & 1,24 & 1,00 & 1,18 & 1,99 & 1,24 & 1,69 & 1,14 & 1,14 & 0,92 & 0,79 & 1,07 & 0,97 & 0,75 & 1,03 & 0,83 & 0,96 & 0,34 & 0,11 \\
\hline
\end{tabular}

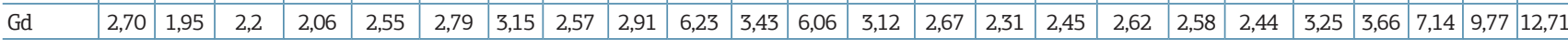
\begin{tabular}{l|l|l|l|l|l|l|l|l|l|l|l|l|l|l|l|l|l|l|l|l|l|l|l|l|l|l|l|l|l|l|}
\hline $\mathrm{Tb}$ & 0,38 & 0,29 & 0,36 & 0,32 & 0,4 & 0,39 & 0,40 & 0,37 & 0,43 & 0,89 & 0,54 & 0,97 & 0,46 & 0,40 & 0,35 & 0,40 & 0,39 & 0,39 & 0,38 & 0,46 & 0,54 & 1,21 & 1,53 & 2,32 \\
\hline
\end{tabular} \begin{tabular}{l|l|l|l|l|l|l|l|l|l|l|l|l|l|l|l|l|l|l|l|l|l|l|l|l|l|l|}
\hline Dy & 1,83 & 1,41 & 1,85 & 1,56 & 1,94 & 2,08 & 2,48 & 1,96 & 2,25 & 5,54 & 2,85 & 5,48 & 2,21 & 1,94 & 1,84 & 2,17 & 1,83 & 1,90 & 1,81 & 3,07 & 3,21 & 7,08 & 9,99 & 14,36 \\
\hline
\end{tabular}

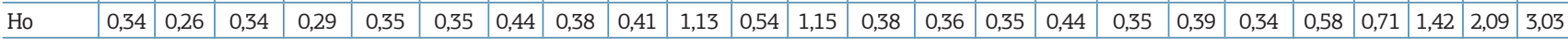
\begin{tabular}{l|l|l|l|l|l|l|l|l|l|l|l|l|l|l|l|l|l|l|l|l|l|l|l|l|l|l|l|l|l|l|l|}
\hline Er & 1,00 & 0,72 & 0,93 & 0,78 & 0,96 & 0,97 & 1,25 & 1,05 & 1,11 & 3,03 & 1,46 & 3,12 & 1,10 & 1,07 & 1,02 & 1,31 & 1,05 & 1,11 & 1,04 & 1,66 & 2,13 & 4,26 & 6,16 & 8,96 \\
\hline
\end{tabular}

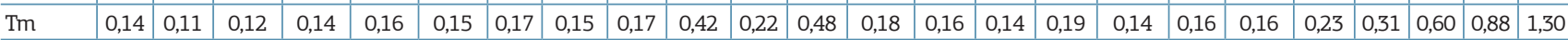

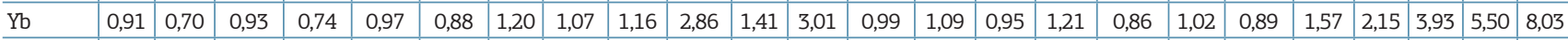

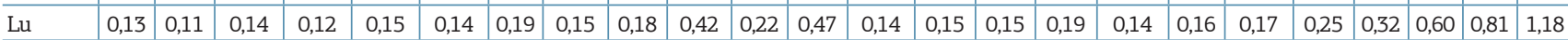

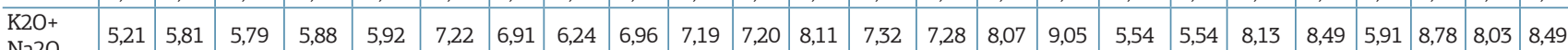

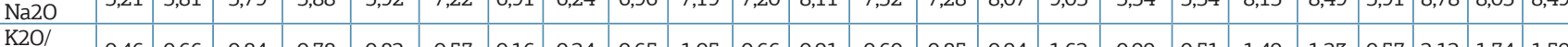

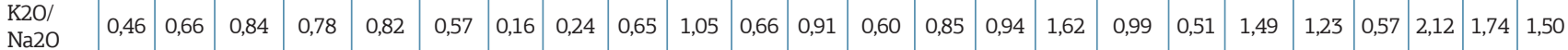

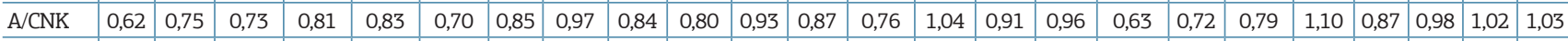
\begin{tabular}{lllllllllll|l|l|l|l|l|l|l|l|l|l|l|l|l|l|l|l|l}
\hline $\begin{array}{l}\text { FeOtot/ } \\
\text { (FeOtot }\end{array}$ & 0,42 & 0,37 & 0,54 & 0,46 & 0,56 & 0,49 & 0,63 & 0,52 & 0,67 & 0,79 & 0,70 & 0,80 & 0,53 & 0,64 & 0,56 & 0,65 & 0,43 & 0,57 & 0,63 & 0,66 & 0,67 & 0,95 & 0,98 & 0,98
\end{tabular}

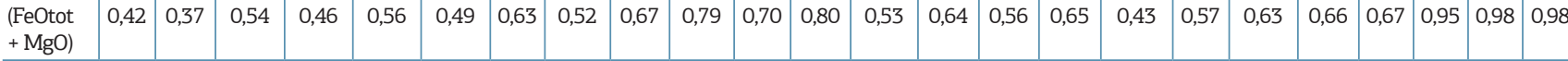

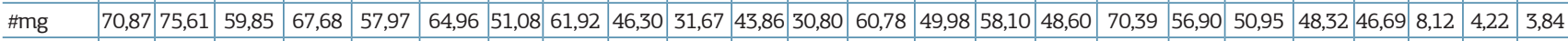

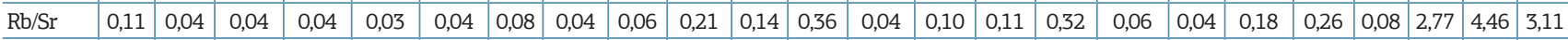

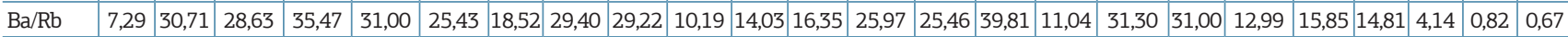
\begin{tabular}{l|l|l|l|l|l|l|l|l|l|l|l|l|l|l|l|l|l|l|l|l|l|l|l|l|}
\hline $\mathrm{Rb} / \mathrm{Zr}$ & 1,07 & 0,38 & 0,48 & 0,42 & 0,48 & 0,32 & 0,35 & 0,37 & 0,43 & 0,69 & 0,66 & 0,53 & 0,49 & 0,92 & 0,69 & 0,59 & 0,78 & 0,44 & 0,56 & 0,81 & 0,32 & 0,86 & 0,81 & 0,72 \\
\hline
\end{tabular}

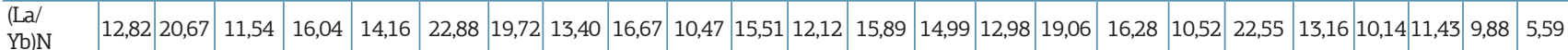

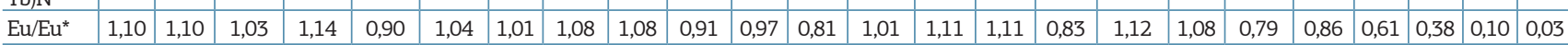

AB: andesito basáltico; TR: traquito; TAB: traquiandesito basáltico; Fácies (Forção Sobreiro): 1-Fácies de fluxo de lava subaérea de composição subalcalina; 2-Fácies de fluxo de lavas subaérea de composição cálcico-alcalina a shoshonítica; 3-Fácies vulcanoclástica subaérea; AN: andesito; DAC: dacito; RL: riolito; TA: traquiandesito; Fácies (Forção Sobreiro): 1-Fácies de fluxo de lava subaérea. 
No diagrama de variação $\mathrm{K}_{2} \mathrm{O} / \mathrm{Na}_{2} \mathrm{O}$ versus $\mathrm{SiO}_{2}$ (Fig. 5A), amostras de traquiandesitos com conteúdos de sílica muito próximos mostram considerável dispersão de valores da razão $\mathrm{K}_{2} \mathrm{O} / \mathrm{Na}_{2} \mathrm{O}$, sugerindo que, pelo menos, parte dessas rochas náo seja comagmática dos andesitos basálticos. Este comportamento dos traquiandesitos também é observado no diagrama $\mathrm{A} / \mathrm{CNK}$ versus $\mathrm{SiO}_{2}$ (Fig. 5B). Os diagramas \#mg versus $\mathrm{SiO}_{2}$ (Fig. $5 \mathrm{C}$ ) e $\mathrm{FeO} /(\mathrm{FeO}+$ $\mathrm{MgO}$ ) versus $\mathrm{SiO}_{2}$ (Fig. 5D) ressaltam as diferenças entre as Formaçôes Sobreiro (\#mg entre 30,08 e 75,61, FeO/(FeO $+\mathrm{MgO})$ entre 0,37 e 0,80) e Santa Rosa (\#mg entre 3,84 e $8,12, \mathrm{FeO} /(\mathrm{FeO}+\mathrm{MgO})$ entre 0,95 e 0,98).

Os baixos conteúdos de $\mathrm{Sr}$ e $\mathrm{Ba}$ e os elevados conteúdos de Rb, Nd, Y e Ta encontrados nos riolitos da Formação Santa Rosa reforçam a distinção entre as rochas dessas unidades e aquelas da Formação Sobreiro (Tab. 1). A disposição dos traquiandesitos no diagrama $\mathrm{Rb} / \mathrm{Sr}$ versus $\mathrm{Rb} / \mathrm{Zr}$ (Fig. 6B) reforça a heterogeneidade de sua química e corrobora a hipótese destas rochas corresponderem a derrames vulcânicos distintos, ou é devida a diferentes graus de interação do magma com material crustal. A sobreposição dos valores das razóes $\mathrm{Ba} / \mathrm{Rb}$ e $\mathrm{Rb} / \mathrm{Sr}$ nos traquiandesitos e andesitos também sustenta a primeira hipótese (Figs. 6A e B). A Formação Santa Rosa tem as mais baixas razóes $\mathrm{Ba} / \mathrm{Rb}(0,67$ a 4,44) e as mais elevadas razôes $\mathrm{Rb} / \mathrm{Sr}(2,77$ a 4,46) (Figs. 6A e B, Tab. 1).

Em diagramas de elementos terras raras (ETR) normalizados ao condrito (Nakamura 1974), observa-se que as amostras da Formação Sobreiro exibem, de modo geral, enriquecimento em ETR leves em relação aos pesa$\operatorname{dos}\left(\mathrm{La}_{\mathrm{N}} / \mathrm{Yb}_{\mathrm{N}}=10,47\right.$ a 22,88, fácies $1 ; \mathrm{La}_{\mathrm{N}} / \mathrm{Yb}_{\mathrm{N}}=12,98 \mathrm{a}$ 19,06, fácies 2; $\mathrm{La}_{\mathrm{N}} / \mathrm{Yb}_{\mathrm{N}}=10,14$ a 22,55, fácies 3) e anomalias de Eu levemente negativas a levemente positivas

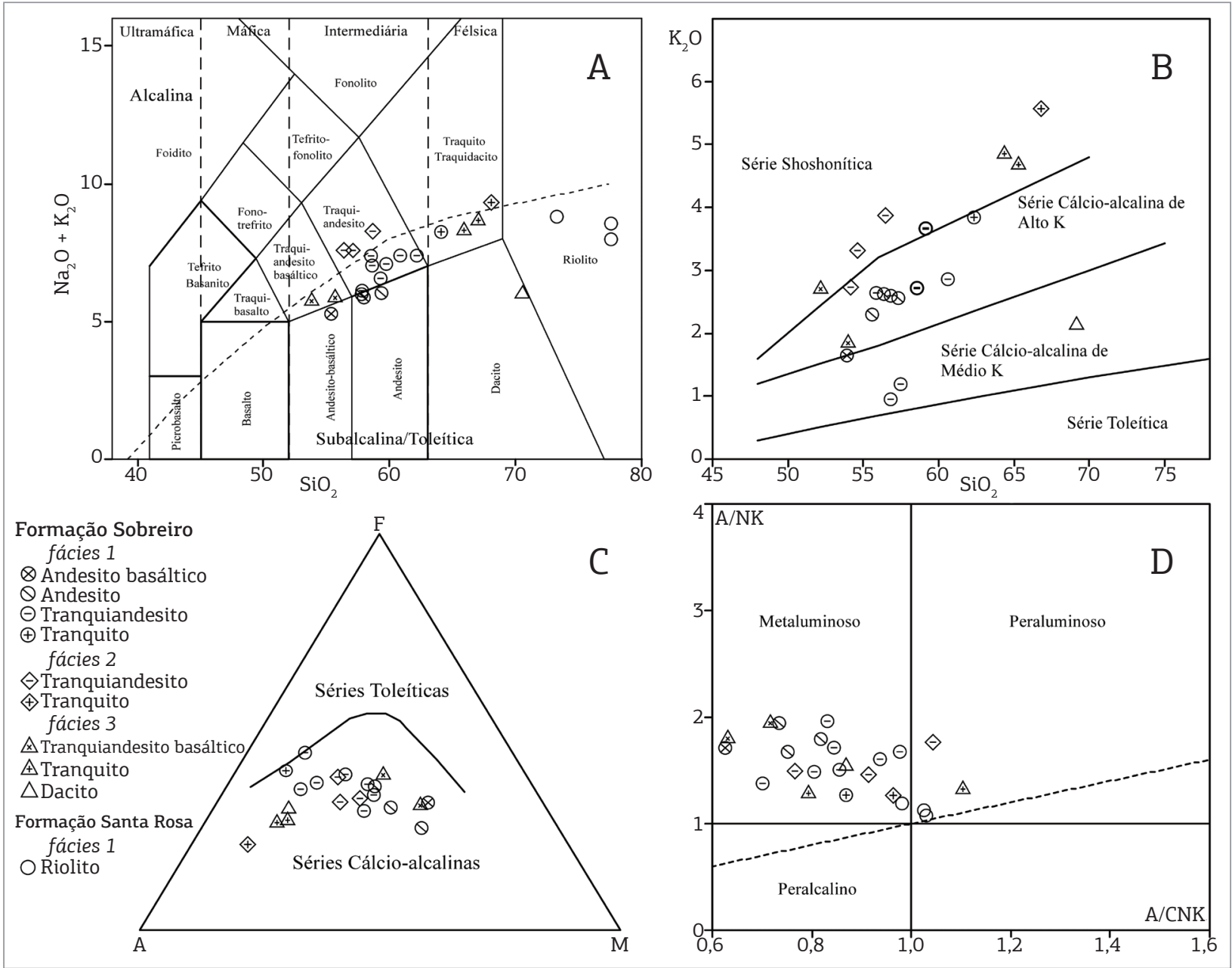

Figura 3. (A) Classificação geoquímica das amostras das formações Sobreiro e Santa Rosa a partir do diagrama TAS (Le Bas et al. 1986, Le Maitre 2002); (B) Distribuição das amostras da Formação Sobreiro, no diagrama $\mathrm{K}_{2} \mathrm{O}$ versus $\mathrm{SiO}_{2}$ (Peccerillo \& Taylor 1976); (C) Distribuição das amostras da Formação Sobreiro no diagrama AFM (Irvine \& Baragar 1971); (D) Distribuição das amostras das formações Sobreiro e Santa Rosa no diagrama de Maniar \& Piccoli (1989), baseado no índice de Shand (1950). 

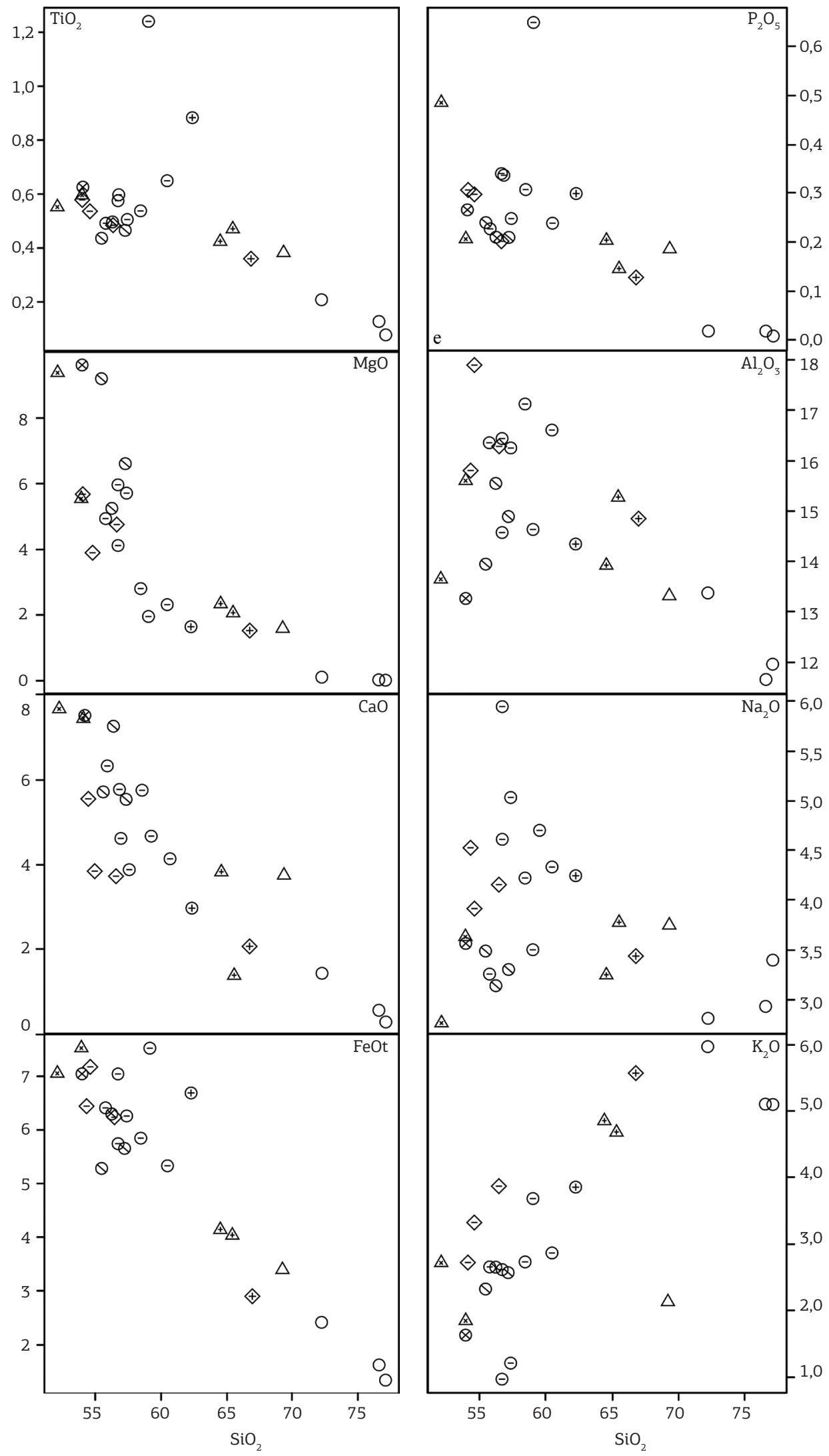

Figura 4. Diagramas de Harker mostrando a distribuição das amostras das formações Sobreiro e Santa Rosa (valores em percentagem em peso). 


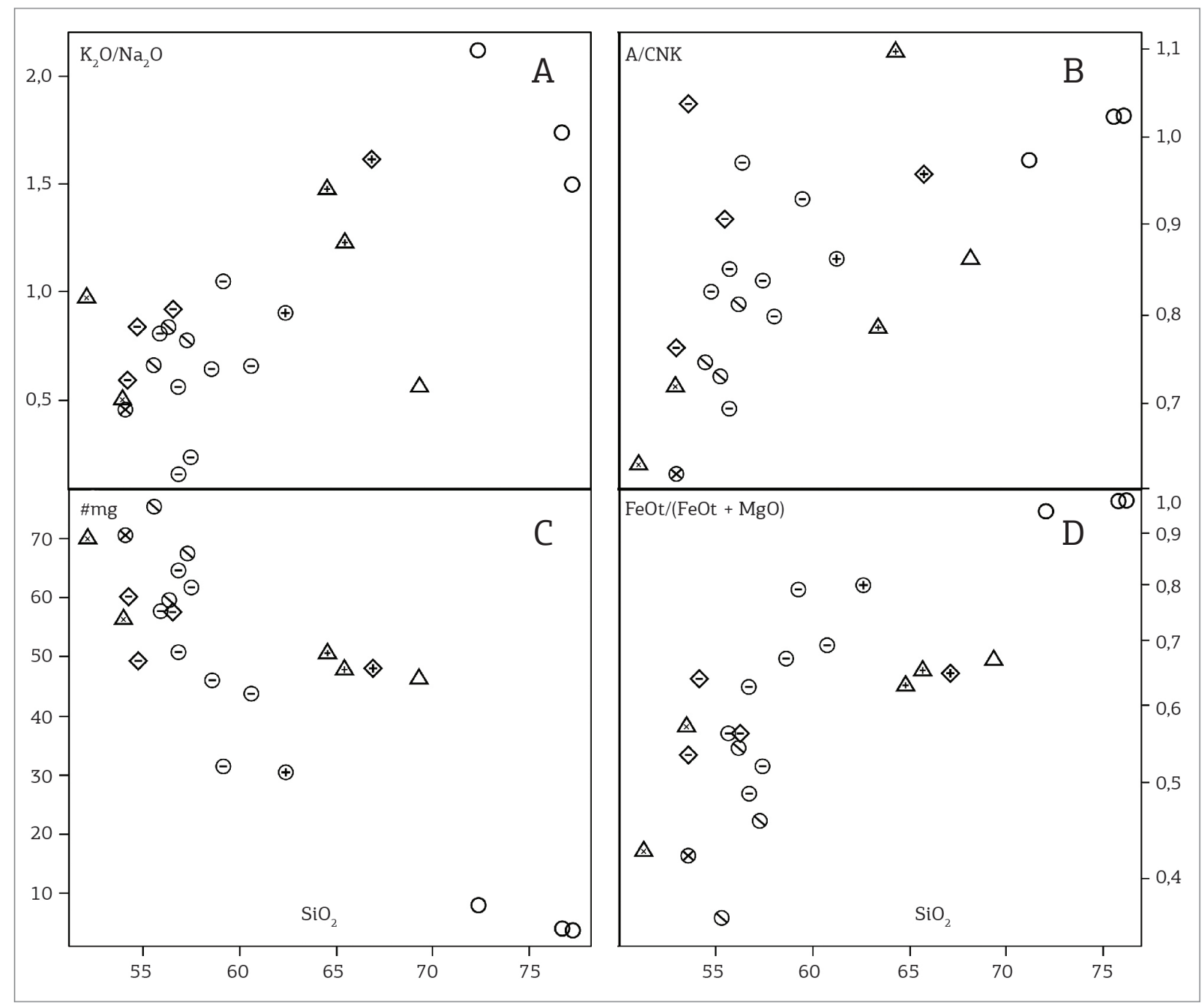

Figura 5. Diagramas de variação das formações Sobreiro e Santa Rosa. (A) $\mathrm{K}_{2} \mathrm{O} / \mathrm{Na}_{2} \mathrm{O}$ versus $\mathrm{SiO}$; (B) $\mathrm{A} / \mathrm{CNK}$ versus $\mathrm{SiO}_{2}$; (C) \#mg versus $\mathrm{SiO}_{2}$; (D) $\mathrm{FeO} /(\mathrm{FeO}+\mathrm{MgO})$ versus $\mathrm{SiO}_{2}$.

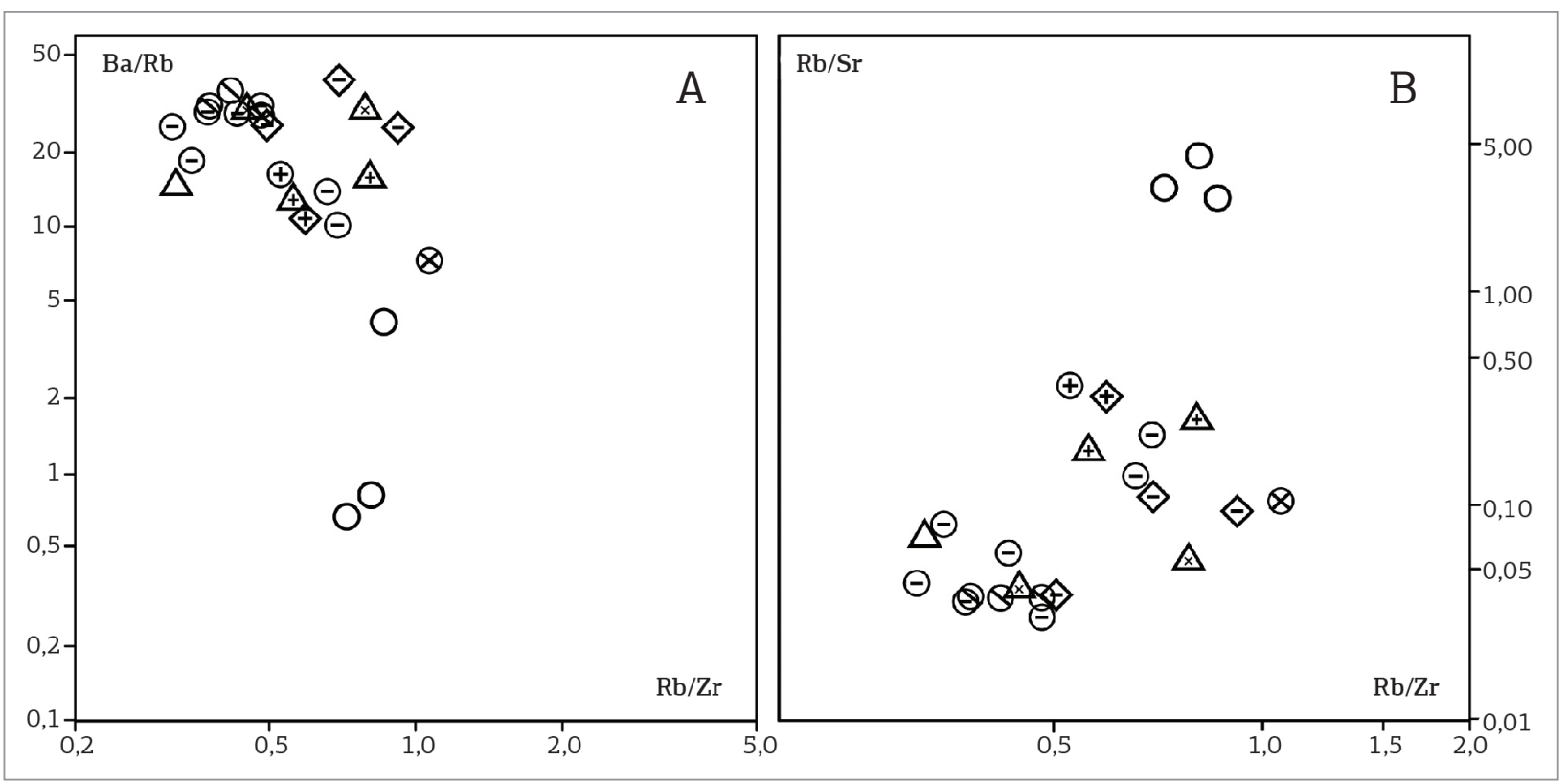

Figura 6. Diagramas geoquímicos das formações Sobreiro e Santa Rosa. (A) Ba/Rb versus $\mathrm{Rb} / \mathrm{Zr}$; (B) $\mathrm{Rb} / \mathrm{Sr}$ versus $\mathrm{Rb} / \mathrm{Zr}$. 


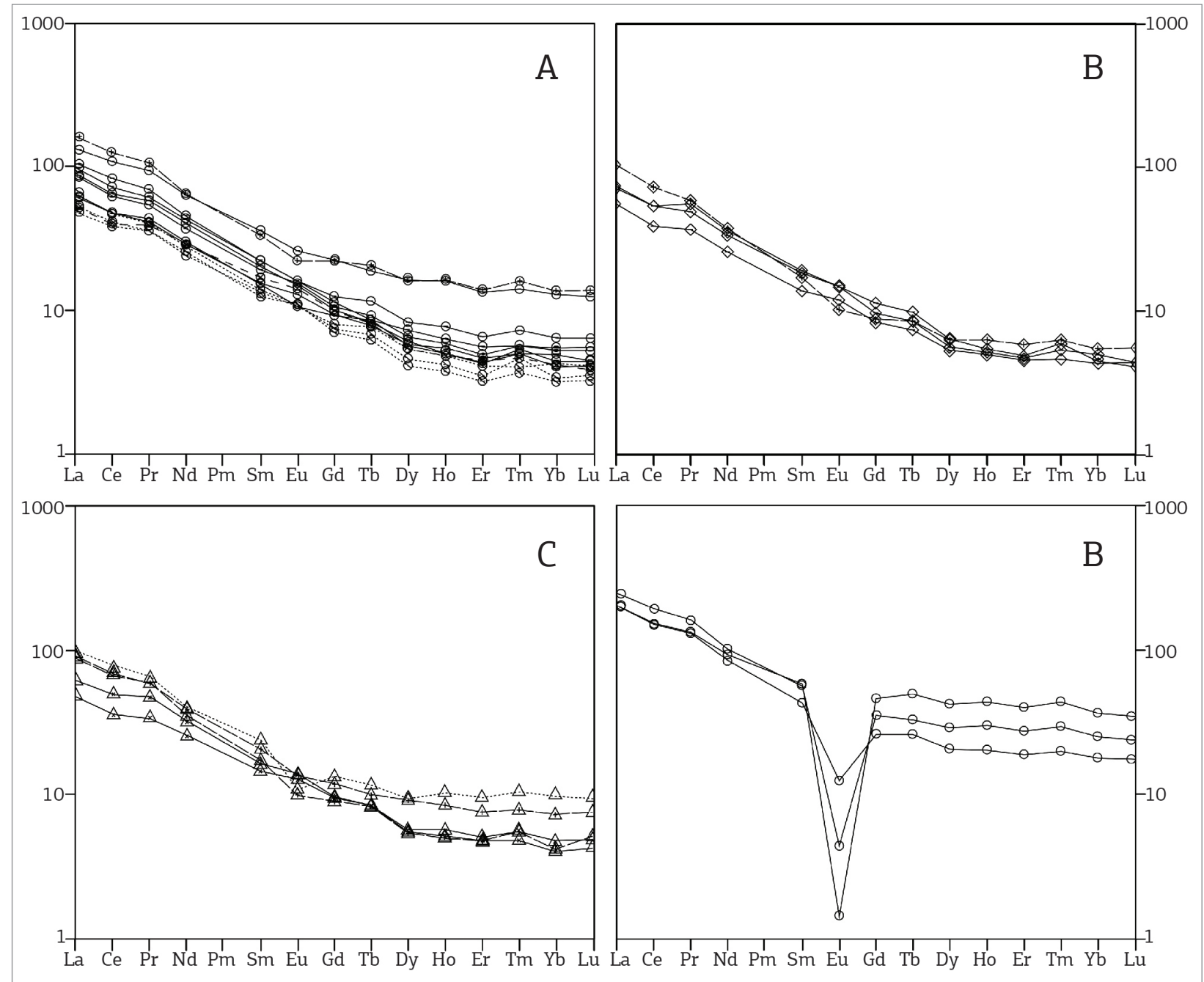

Figura 7. Padrões de elementos terras raras normalizados ao condrito (Nakamura 1974). (A) Fácies 1; (B) Fácies 2; (C) Fácies 3; (Formação Sobreiro); (D) Fácies 1 (Formação Santa Rosa).

$\left(\mathrm{Eu} / \mathrm{Eu}^{*}=0,81\right.$ a 1,14 , fácies $1 ; \mathrm{Eu} / \mathrm{Eu}^{*}=0,83$ a 1,11 , fácies 2 ; $\mathrm{Eu} / \mathrm{Eu}^{*}=0,61$ a 1,12, fácies 3), com padrões típicos das séries calcioalcalinas (Figs. 7A a C). A quase perfeita sobreposição dos padrôes das amostras de lapili-tufos da fácies 3 (Fig. 7C) pode indicar que, embora geograficamente descontínuos, esses depósitos tenham sido formados a partir de materiais semelhantes entre si e diferentes em relação aos tufos de cristais. O trend de ETR dos riolitos da Formação Santa Rosa indica moderado a baixo fracionamento dos ETR pesados em relação aos leves $\left(\mathrm{La}_{\mathrm{N}} / \mathrm{Yb}_{\mathrm{N}}=\right.$ $5,59$ a 11,43$)$ e pronunciada anomalia negativa de $\mathrm{Eu}(\mathrm{Eu} /$ $\mathrm{Eu}^{*}=0,38$ a 0,03$)$, denotando padrão semelhante ao de granitos tipo A (Fig. 7D).

Nos diagramas $\mathrm{FeOt} / \mathrm{MgO}$ versus $\mathrm{Zr}+\mathrm{Nb}+\mathrm{Ce}+\mathrm{Y}$ (Fig. $8 \mathrm{~A})$ e $\left(\mathrm{K}_{2} \mathrm{O}+\mathrm{Na}_{2} \mathrm{O}\right) / \mathrm{CaO}$ versus $\mathrm{Zr}+\mathrm{Nb}+\mathrm{Ce}+\mathrm{Y}$ (Fig. 8B) de Whalen, Currie \& Chappell (1987), os riolitos da Formação Santa Rosa plotam no campo dos granitos tipo A, enquanto os diversos litotipos da Formação
Sobreiro plotam no campo dos granitos I, S, M não fracionados. No diagrama de afinidade tectônica Ta versus $\mathrm{Yb}$ (Fig. 8C) de Pearce, Harris \& Tindle (1984), a Formação Santa Rosa mostra afinidade tectônica intraplacas dominante, enquanto a Formação Sobreiro plota no campo de granitos de arco vulcânico. Segundo a classificação geotectônica a partir do diagrama Th versus $\mathrm{Hf} / 3$ versus $\mathrm{Ta}$ (Fig. 8D) de Wood (1980), a Formação Sobreiro se posiciona no campo de basaltos calcioalcalinos.

\section{Comparações}

Desde os primeiros trabalhos realizados na região de São Félix do Xingu, as rochas vulcânicas de composiçôes predominantemente intermediárias foram agrupadas na Formação Sobreiro (IDESP 1970, Macambira \& Vale 1997, Teixeira et al. 2002). Juliani \& Fernandes (2010), em trabalhos de mapeamento na área oeste/sudoeste de Sáo Félix do Xingu, caracterizaram um amplo 


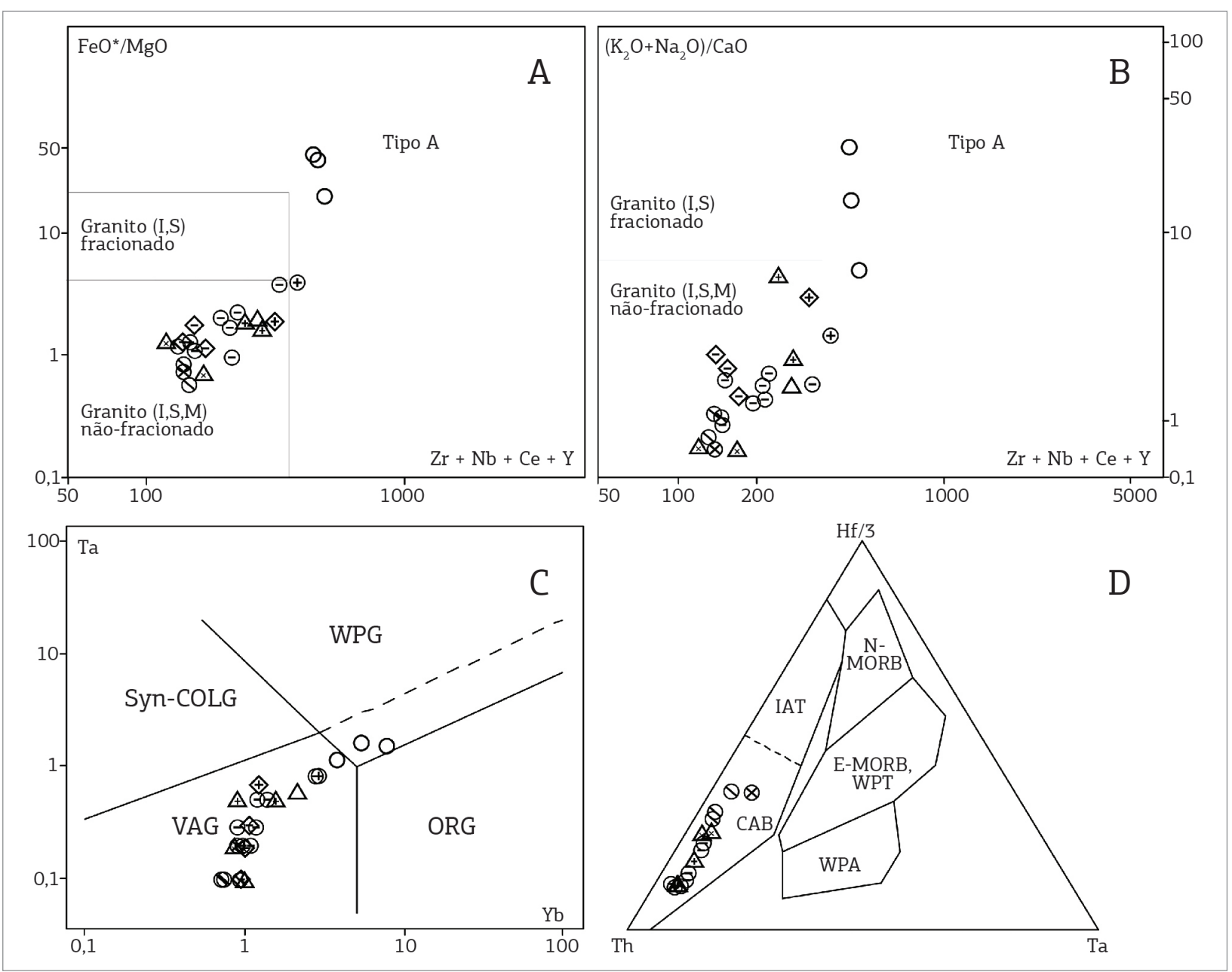

Figura 8. Diagramas de afinidade tectônica das formações Sobreiro e Santa Rosa. (A) $\mathrm{FeO} / \mathrm{MgO}$ versus $\mathrm{Zr}+\mathrm{Nb}+$ $\mathrm{Ce}+\mathrm{Y}$ (Whalen, Currie \& Chappell 1987); (B) $\left(\mathrm{K}_{2} \mathrm{O}+\mathrm{Na}_{2} \mathrm{O}\right) / \mathrm{CaO}$ versus $\mathrm{Zr}+\mathrm{Nb}+\mathrm{Ce}+\mathrm{Y}$ (Whalen, Currie \& Chappell 1987); (C) Ta versus Yb, (Pearce, Harris \& Tindle 1984); (D) Th versus Hf/3 versus Ta (Wood 1980). VAG: granitos de arco vulcânico; syn-COLG: granitos sin-colisionais; WPG: granitos intraplacas; ORG: granitos de cordeira oceânica; CAB: basaltos calcioalcalinos; IAT: toleítos de arco de ilha; WPA: basaltos intraplaca alcalinos; WPT: basaltos intraplaca toleíticos; E-MORB: Enriched Mid-Ocean Ridge Basalt; N-MORB: Normal Mid-Ocean Ridge Basalt.

e extenso vulcanismo bimodal efusivo e explosivo de idade Paleoproterozoica que teria gerado duas unidades vulcânicas quimicamente distintas - a unidade basal, correlacionada à Formação Sobreiro e a unidade topo, denominada Formação Santa Rosa.

À exceção dos lapili-tufos autoclásticos, todos os demais litotipos da Formação Sobreiro descritos por Juliani e Fernandes (2010), foram identificados na área sul de São Félix do Xingu, sugerindo, portanto, se tratar da mesma unidade. Quanto à Formação Santa Rosa, na área sul foram reconhecidas apenas ocorrências restritas de fácies de fluxo de lavas de composição félsica, não sendo encontrada nenhuma ocorrência de fácies vulcanoclásticas. Esse fato permite pensar que o material piroclástico ejetado pelos processos de vulcanismo explosivo ocorrido na área oeste/ sudoeste não se depositou a longas distâncias ou foi rapidamente erodido.

A classificação geoquímica das rochas vulcânicas das áreas sul e oeste/sudoeste a partir do diagrama TAS (Le Bas et al. 1986; Fig. 9A) mostra perfeita similaridade entre as mesmas. A predominância dos traquiandesitos em relação aos andesitos basálticos, andesitos, dacitos e traquitos da Formação Sobreiro é igualmente observada em ambas as áreas supramencionadas. Ao mesmo tempo, as poucas amostras de traquiandesitos e traquitos calcioalcalinos a shoshoníticos encontradas na área sul é observada na classificação das vulcânicas da área oeste/sudoeste. Quanto à Formação Santa Rosa, a classificação a partir do diagrama TAS exibe estreita relação entre os riolitos de ambas as margens do Rio Xingu. Além disso, os conteúdos de $\mathrm{SiO}_{2}$ 


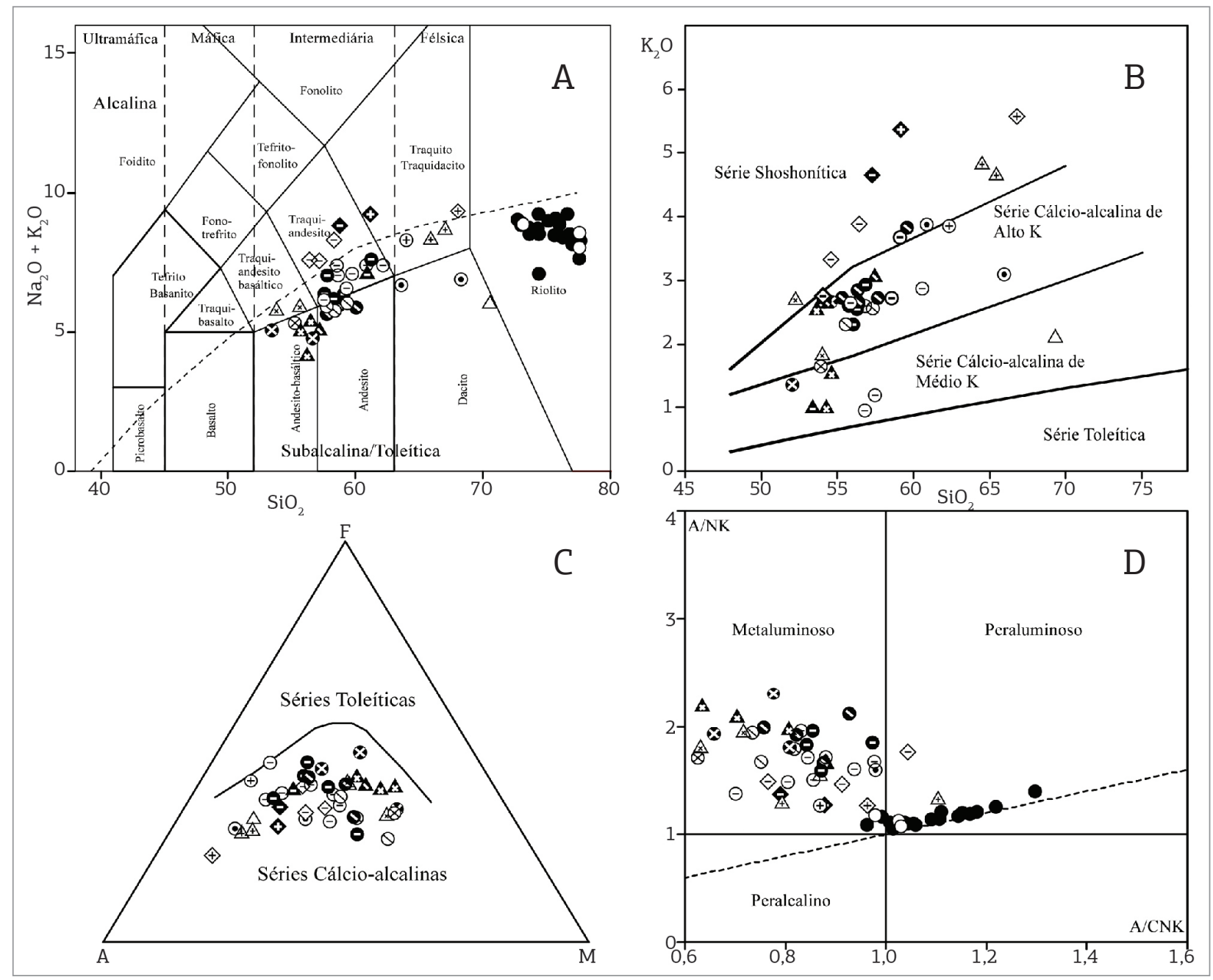

Figura 9. Diagramas comparativos das formações Sobreiro e Santa Rosa das áreas sul (este trabalho) e oeste/ sudoeste (Fernandes, Lamarão \& Teixeira 2006, Fernandes 2009, Juliani \& Fernandes 2010) de São Félix do Xingu. (A) Classificação geoquímica a partir do diagrama TAS (Le Bas et al. 1986; Le Maitre 2002); (B) Distribuição das amostras no diagrama $\mathrm{K}_{2} \mathrm{O}$ versus $\mathrm{SiO}_{2}$ (Peccerillo \& Taylor 1976); (C) Distribuiç̧ão das amostras no diagrama AFM (Irvine \& Baragar 1971); (D) Distribuição das amostras no diagrama de Maniar \& Piccoli (1989), baseado no índice de Shand (1943). Em branco, amostras da área sul; em preto, amostras das áreas oeste e sudoeste.

e as razóes $\mathrm{K}_{2} \mathrm{O} / \mathrm{Na}_{2} \mathrm{O}$ tanto da Formação Sobreiro (área sul: $\mathrm{SiO}_{2}=53,97$ a 69,21\%; $\mathrm{K}_{2} \mathrm{O} / \mathrm{Na}_{2} \mathrm{O}=0,16$ a 1,62; área oeste sudoeste: $\mathrm{SiO}_{2}=51,93$ a 65,91\%; $\mathrm{K}_{2} \mathrm{O} / \mathrm{Na}_{2} \mathrm{O}=0,39$ a 1,52) quanto da Formação Santa Rosa (área sul: $\mathrm{SiO}_{2}=$ 72,27 a $77,14 \%, \mathrm{~K}_{2} \mathrm{O} / \mathrm{Na}_{2} \mathrm{O}=1,50$ a 2,12; área oeste/sudoeste: $\mathrm{SiO}_{2}=69,94$ a $76,67 \% ; \mathrm{K}_{2} \mathrm{O} / \mathrm{Na}_{2} \mathrm{O}=1,31$ a 3,19) são perfeitamente sobrepostos.

No diagrama $\mathrm{K}_{2} \mathrm{O}$ versus $\mathrm{SiO}_{2}$ de Peccerillo \& Taylor (1976) (Fig. 9B), é possível perceber que as amostras da fácies de fluxo de lavas e composição subalcalina da área oeste/ sudoeste, semelhante aos vulcanitos relacionados a processos de vulcanismo efusivo de composição subalcalina da área sul, plotam predominantemente no campo da série calcioalcalina de alto $\mathrm{K}$, com a dispersão de algumas amostras para os campos de baixo $\mathrm{K}$ e da série shoshonítica. Essa distribuição reforça a hipótese dessas rochas pertencerem à mesma unidade. As rochas calcioalcalinas a shoshoníticas da área oeste/sudoeste, nesse diagrama alinham-se perfeitamente às calcioalcalinas a shoshoníticas da área sul, possivelmente, denotando a existência de uma fácies dominantemente shoshonítica na Formação Sobreiro. Fernandes et al. (2011), no entanto, interpretam que tais rochas adquirem tal comportamento em função de processos de metassomatismo potássico. A boa preservação da assembleia de fenocristais das amostras da área sul descarta tal possibilidade. A dispersão das amostras das fácies vulcanoclásticas de ambas as áreas aqui tratadas nos campos das séries de baixo e alto $\mathrm{K}$, chegando até a série shoshonítica, comprova a heterogeneidade 


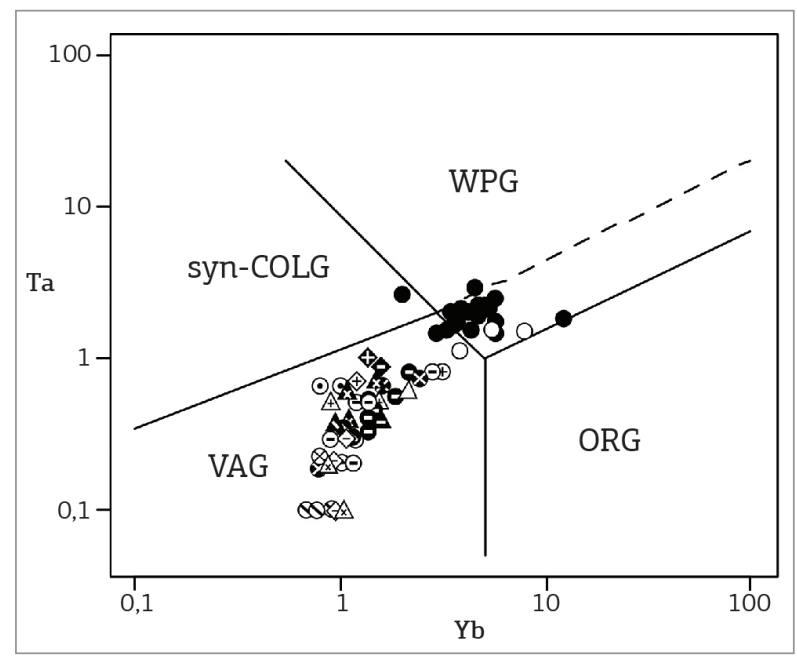

Figura 10. Distribuição das amostras das formações Sobreiro e Santa Rosa, áreas sul (este trabalho) e oeste/sudoeste (Fernandes Lamarão \& Teixeira 2006, Fernandes 2009, Juliani \& Fernandes 2010) de São Félix do Xingu, no diagrama de afinidade tectônica $\mathrm{Ta}$ versus $\mathrm{Yb}$, (Pearce, Harris \& Tindle 1984). Em branco, amostras da área sul; em preto, amostras das áreas oeste e sudoeste.

dos materiais que as compóem. A hipótese dos andesitos basálticos da Formação Sobreiro e, pelo menos, parte dos traquiandesitos, não estarem vinculados a processos de cristalização fracionada é corroborada pela distribuição dos vulcanitos da área oeste/sudoeste no diagrama de Peccerillo \& Taylor (1976) (Fig. 9B).

A partir do diagrama AFM de Irvine e Baragar (1971) (Fig. 9C), percebe-se que o caráter calcioalcalino é igualmente demonstrado pelos vulcanitos das áreas sul e oeste/sudoeste.

No diagrama de aluminosidade (Fig. 9D), é possível perceber que o caráter dominantemente metaluminoso a fracamente peraluminoso das rochas vulcânicas da área sul é igualmente indicado pelas rochas vulcânicas calcioalcalinas da área oeste/sudoeste, reforçando mais uma vez a hipótese dessas rochas pertencerem à mesma unidade. Da mesma forma, o caráter peraluminoso a fracamente metaluminoso observado nas amostras da Formação Santa Rosa da área sul é indicado pelos riolitos da área oeste/sudoeste.

No que concerne aos ETR, as razôes $(\mathrm{La} / \mathrm{Yb}) \mathrm{N}$ das fácies de fluxo de lavas de composição subalcalina da Formação Sobreiro das áreas sul $((\mathrm{La} / \mathrm{Yb}) \mathrm{N}=10,14$ a 22,88$)$ e oeste/sudoeste $((\mathrm{La} / \mathrm{Yb}) \mathrm{N}=9,52$ a 23,88$)$ são perfeitamente sobrepostas, sinalizando para uma continuidade lateral da Formação Sobreiro em ambas as margens do Rio Xingu. Valores muito semelhantes das razões $(\mathrm{La} / \mathrm{Yb}) \mathrm{N}$ também são encontrados nas fácies de composição calcioalcalina a shoshonítica (área sul: $(\mathrm{La} / \mathrm{Yb}) \mathrm{N}=12,98$ a 19,06); área oeste/sudoeste: (La Yb) $\mathrm{N}=15,20$ a 20,73) e nas fácies vulcanoclásticas (área sul: (La/Yb)N = 10,14 a 22,55); área oeste/sudoeste: $(\mathrm{La} / \mathrm{Yb}) \mathrm{N}=8,85$ a 17,72$)$. Da mesma forma, os riolitos das fácies de fluxo de lavas mostram razóes $(\mathrm{La} \mathrm{Yb}) \mathrm{N}$ muito semelhantes (área sul: $(\mathrm{La} / \mathrm{Yb}) \mathrm{N}=5,59$ a 11,43); área oeste/sudoeste: $(\mathrm{La} / \mathrm{Yb}) \mathrm{N}=8,60$ a 15,64).

No diagrama $\mathrm{Ta}$ versus $\mathrm{Yb}$ de Pearce, Harris \& Tindle (1984) (Fig. 10), é possível perceber que todas as amostras da Formação Sobreiro, tanto da área sul quanto da área oeste/sudoeste, se agrupam no campo dos granitos de arco vulcânico. Os riolitos da Formação Santa Rosa da área oeste/sudoeste, plotam, de modo geral, no campo dos granitos intraplacas, com leve dispersão para o campo de granitos de arco vulcânico. Um ambiente tectônico sin-colisional é sugerido por uma única amostra de riolito da área oeste/sudoeste, podendo simplesmente representar maior enriquecimento em $\mathrm{Yb}$ nessa amostra.

\section{DISCUSSÃO}

Fenocristais de hornblenda e plagioclásio são dominantes nos andesitos estudados, enquanto em algumas amostras de traquiandesitos e andesitos figuram, além desses dois minerais, clinopiroxênio como fase importante ou mais abundante. Tais associaçôes mineralógicas sugerem que, pelo menos, parte dos traquiandesitos não tenha derivado dos andesitos basálticos por processos de cristalização fracionada. Os diagramas geoquímicos de $\mathrm{K}_{2} \mathrm{O}$ versus $\mathrm{SiO}_{2}$ (1976), AFM , $\mathrm{K}_{2} \mathrm{O} / \mathrm{Na}_{2} \mathrm{O}$ versus $\mathrm{SiO}_{2}, \mathrm{Ba} / \mathrm{Rb}$ versus $\mathrm{Rb} /$ $\mathrm{Zr}$ e $\mathrm{Rb} / \mathrm{Sr}$ versus $\mathrm{Rb} / \mathrm{Zr}$, além dos padrōes de ETR fornecem a mesma indicação.

A existência de duas fácies, geoquimicamente distintas, uma dominantemente calcioalcalina e outra dominantemente shoshonítica na Formação Sobreiro indica o caráter transicional de série calcioalcalina a shoshonítica para esta Formação.

Embora pouco abundantes e espaçados na área estudada, a existência de afloramentos de rochas vulcanoclásticas (Fig. 2) pode sugerir que o vulcanismo explosivo da região de São Félix do Xingu teve extensa expressão geográfica.

As afinidades com granitos de arco magmático da Formação Sobreiro, e com gratitos intraplaca da Formação Santa Rosa (Fig. 8C), encontram consonância com a história de formação da porção sul do Cráton Amazônico que, segundo Tassinari \& Macambira (2004) e Santos et al. (2006), está vinculada a uma série de eventos orogenéticos, ocorridos entre 2,0 e 1, $87 \mathrm{Ga}$, que culminaram com a geração de granitos anorogênicos. 
Discussôes mais aprofundadas sobre o ambiente tectônico dessas unidades dependem da obtenção de dados que vão além do escopo deste trabalho.

Todos os diagramas de classificação geoquímica (Figs. 9A a D), ambiente tectônico (Fig. 10) e os valores das razôes $(\mathrm{La} / \mathrm{Yb}) \mathrm{N}$ das rochas vulcânicas e vulcanoclásticas das áreas sul e oeste/sudoeste de São Félix do Xingu, evidenciam a perfeita correlação das Formações Sobreiro e Santa Rosa em ambas as margens do Rio Xingu.

\section{CONCLUSÃO}

$\mathrm{Na}$ área sul de São Félix do Xingu afloram rochas vulcânicas e vulcanoclásticas diversas pertencentes, sobretudo, à Formação Sobreiro e, subordinadamente, à Formação Santa Rosa. Estas duas unidades representam o Grupo Uatumá.

A Formação Sobreiro é formada por três fácies: fácies de fluxo de lavas subaérea de composição subalcalina; fácies de fluxo de lavas subaérea de composição calcioalcalina a shoshonítica; e fácies vulcanoclástica subaérea. A Formação Santa Rosa é constituída por riolitos com aspecto típico de fluxo de lavas e foram aqui nomeados fácies de fluxo de lavas subaérea.

Rochas de cor cinza escura, afaníticas, microporfiríticas, comumente porfiríticas, ricas em fenocristais com aspecto de fluxo de lavas, são as principais representantes da Formação Sobreiro. Rochas com aspecto vulcanoclástico, constituídas essencialmente por fragmentos de cristais e/ou líticos são encontradas subordinadamente. Os riolitos da Formação Santa Rosa são de cor rosa e variam de afaníticas a porfiríticas.
Em termos geoquímicos, a Formação Sobreiro é representada dominantemente por traquiandesitos, e subordinadamente por andesitos basálticos, andesitos, traquitos e dacitos, todos subalcalinos. Além destas rochas, traquiandesitos e traquitos calcioalcalinos a shoshoníticos são litotipos encontrados subordinadamente. A Formação Santa Rosa é representada por riolitos.

A Formação Sobreiro tem caráter metaluminoso a fracamente peraluminoso, é dominantemente calcioalcalina, com algumas amostras de assinatura transicional calcioalcalina a shoshonítica e apresenta afinidade tectônica de arco vulcânico. A Formação Santa Rosa forma uma série magmática peraluminosa a fracamente metaluminosa, apresenta afinidade tipo A relacionada a ambiente tectônico intraplacas.

As rochas vulcânicas da área sul apresentam perfeita correlação petrográfica, geoquímica e tectônica com os vulcanitos da área oeste/sudoeste de São Félix do Xingu.

\section{AGRADECIMENTOS}

Ao Programa Nacional de Cooperação AcadêmicaPROCAD (Projeto 0096/05-9) e ao Instituto Nacional de Ciência e Tecnologia de Geociências da Amazônia/Conselho Nacional de Desenvolvimento Científico e Tecnológico (INCTGEOCIAM/CNPq) pelo apoio financeiro em diversas etapas, ao Programa de Pós-graduação em Geologia e Geoquímica da UFPA pelo apoio e infraestrutura disponibilizados, ao Prof. Carlos M. D. Fernandes, ao Prof. Roberto Dall'Agnol e à Profa. Gilmara R. L. Feio pelas críticas e sugestôes, ao Geólogo Jardel Mesquita pelo apoio na fase de campo, ao Prof. Carlos A. Sommer pelo repasse de conhecimento e acervo bibliográfico além de sugestóes feitas à primeira autora.

\section{REFERÊNCIAS}

Avelar V.G., Lafon J.M., Correia Jr., F.C., Macambira E.M.B. 1999. O magmatismo arqueano da região de Tucumã-Província Mineral de Carajás: novos resultados geocronológicos. Revista Brasileira de Geociências, 29(4):454-460.

De La Roche H., Laterrier J., Grandclaude P., Marchal M. 1980. A classification of volcanic and plutonic rocks using R1R2-diagram and major-element analyses - Its relationships with current nomenclature. Chemical Geology, 29(1-4):183-210.

Fernandes C.M.D., Lamarão C.N., Teixeira N.P. 2006. O vulcanismo bimodal do tipo Uatumã da região de São Félix do Xingu (PA), Província Mineral de Carajás. Revista Brasileira de Geociências, 36(3):565-576

Fernandes C.M. 2009. Estratigrafia e Petrogênese das Seqüências Vulcânicas Paleoproterozóicas na região de São Félix do Xingu (PA), Província Mineral de Carajás. Tese de Doutorado, Instituto de Geociências, Universidade de São Paulo, São Paulo, 190 p.
Fernandes C.M.D., Juliani, C., Monteiro, L.V.S, Lagler, B., Missas, C.M.E. 2011. High-K calc-alkaline to A-type fissure-controlled volcanoplutonism of the São Félix do Xingu region, Amazonian craton, Brazil: Exclusively crustal sources or only mixed $\mathrm{Nd}$ model ages? Journal of South American Earth Sciences, 32(4):351-368.

Fisher R.V. 1966. Rocks composed of volcanic fragments and their classification. Earth Science Reviews, 1(4):287-298.

Instituto de Desenvolvimento Econômico-Social do Pará (IDESP). 1970. Programa de Pesquisa de Carvão Mineral na Bacia do Rio Fresco, afluente do Rio Xingu, Estado do Pará. Relatório de Pesquisa II, Fase 2. Belém. 21p.

Irvine T.N. \& Baragar W.R.A. 1971. A guide to the chemical classification of the common volcanic rocks. Canadian Journal of Earth Sciences, 8(5):523-546. 
Juliani C. \& Fernandes C.M.D. 2010. Well-preserved Late Paleoproterozoic volcanic centers in the São Félix do Xingu region, Amazonian Craton, Brazil. Journal of Volcanology and Geothermal Research, 191(3-4):167-179.

Le Bas M.J., Le Maitre R.W., Streckeizen A., Zanettin B. 1986. A chemical classification of volcanic rocks based on the total alkalisilica diagram. Journal of Petrology, 27(3):745-750.

Le Maitre R.W. 2002. A classification of igneous rocks and glossary of terms. 2 ed. London, Cambridge, 193 p.

Macambira E.M.B. \& Vale A.G. 1997. São Félix do Xingu: folha SB.22Y-B, Estado do Pará, escala 1:250.000. Programa Levantamentos Geológicos Básicos do Brasil (PLGB). Texto Explicativo. Brasília, CPRM, $344 \mathrm{p}$.

Machado N., Lindenmayer Z., Krogh T.E., Lindenmayer D. 1991. U-Pb geochronology of Archean magmatism and basement reactivation in the Carajás area, Amazon shield, Brazil. Precambrian Research, 49(3-4):329-354

Maniar P.D. \& Piccoli, P.M. 1989. Tectonic discrimination of granitoids. Geological Society of America Bulletin, 101(5):635-643.

McPhie J., Doyle M. \& Allen R. 1993. Volcanic Textures. A Guide to the interpretation of textures in volcanic rocks. University of Tasmania, Australia, 198 p.

Nakamura N. 1974. Determination of REE, Ba, Fe, Mg, Na e K in carbonaceous and ordinary chondrites. Geochimica et Cosmochimica Acta, 38(5):757-775.

Pearce J.A., Harris N.B.W., Tindle A.B. 1984. Trace element discrimination diagrams for the tectonic interpretation of granitic rocks. Journal of Petrology, 25(4):956-983.

Peccerilo A. \& Taylor S.R. 1976. Geochemistry of Eoceno CalcAlkaline Volcanic Rocks from the Kastamonu Area, Northern Turkey. Contributions to Mineralogy and Petrology, 58:63-81.

Pinho S.C.C., Fernandes C.M.D., Teixeira N.P., Paiva Jr. A.L., Cruz V.L., Lamarão C.N., et al. 2006. O magmatismo paleoproterozóico da região de São Félix do Xingu, Província Estanífera do sul do Pará: Petrografia e Geocronologia. Revista Brasileira de Geociências, 36:793-802.

Santos J.S.O., Hartmann L.A., Faria M.S., Riker S.R., Souza M.M., Almeida M.E., et al. 2006. A compartimentação do Cráton Amazonas em províncias: avanços ocorridos no período 2000-2006. In: SBG. Simpósio de Geologia da Amazônia, 9, Belém. Resumos Expandidos, Belém, (CD-ROM).

Silva G.G., Lima J.J.C., Andrade A.R.F., Issler R.S., Guimarães G. 1974. Geologia. In: Projeto Radam Brasil. Folha SC.22/Tocantins. Rio de Janeiro, DNPM, v. 4, 143 p.

Shand S. J. 1950. Eruptive rocks their genesis, composition, classification e their relation to ore deposit. 4 ed. London, Thomas Murby, 488 p.

Tassinari C.C.G. \& Macambira M.J.B. 2004. Evolução tectônica do Cráton Amazônico. Geologia do Continente Sul Americano. In: Almeida F.F.M., Mantesso-Neto V., Bartorelli A., Carneiro C.D.R., Brito Neves B.B. São Paulo, BECA: 471-486.

Teixeira N.P., Bettencourt J.S., Moura C.A.V., Dall'Agnol R., Macambira E.M.B. 2002. Archean crustal sources for Paleoproterozoic tinmineralized granites in the Carajás Province, SSE Pará, Brazil: $\mathrm{Pb}-\mathrm{Pb}$ geochronology and Nd isotope geochemistry. Precambrian Research, 119:329-353.

Vasquez L.V., Rosa-Costa L.R., Silva C.G., Ricci P.F., Barbosa J.O., Klein E. L., et al. 2008. Geologia e Recursos Minerais do Estado do Pará: Sistema de Informações Geográficas - SIG: texto explicativo dos mapas Geológico e Tectônico e de Recursos Minerais do Estado do Pará. Organizadores, Vasquez M. L., Rosa-Costa L. T. Escala 1:1.000.000. Belém: CPRM.

Wirth K.R., Gibbs A.K., Olszewski Jr W.J. 1986. U-Pb ages of zircões from the Grão Pará Group and Serra dos Carajás Granite, Pará, Brazil. Revista Brasileira de Geociências, 16:195-200.

Wood D.A. 1980. The application of a Th-Hf-Ta diagram to problems of tectonomagmatic classification and to establishing the nature of crustal contamination of basaltic lavas of the British Tertiary volcanic province. Earth and Planetary Science Letters, 50(1):11-30.

Whalen J.W., Currie K.L., Chappell B.W. 1987. A-type granites: geochemical characteristics, discrimination and petrogenesis. Contributions of Mineralogy and Petrology, 95:407-419.

Arquivo digital disponível on-line no site www.sbgeo.org.br 